\title{
A Multiobjective Optimization of the Welding Process in Aluminum Alloy (AA) 6063 T4 Tubes Used in Corona Rings Through Normal Boundary Intersection and Multivariate Techniques
}

\section{Eduardo Rivelino Luz ( $\nabla$ eluz7777@gmail.com )}

Federal University of Itajubá: Universidade Federal de Itajuba

\section{Estevão Luiz Romão}

Federal University of Itajubá: Universidade Federal de Itajuba

\section{Simone Carneiro Streitenberger}

Federal University of Itajubá: Universidade Federal de Itajuba

\section{Leonardo Ribeiro Mancilha}

Federal University of Itajubá: Universidade Federal de Itajuba

\section{Anderson Paulo de Paiva}

Federal University of Itajubá: Universidade Federal de Itajuba

\section{Pedro Paulo Balestrassi}

Federal University of Itajubá: Universidade Federal de Itajuba

\section{Research Article}

Keywords: Aluminum welding, Design of experiments, Multiobjective constrained optimization, Factor analysis, Simultaneous confidence intervals

Posted Date: May 27th, 2021

DOI: https://doi.org/10.21203/rs.3.rs-531184/v1

License: (9) This work is licensed under a Creative Commons Attribution 4.0 International License. Read Full License

Version of Record: A version of this preprint was published at The International Journal of Advanced Manufacturing Technology on August 9th, 2021. See the published version at https://doi.org/10.1007/s00170-021-07761-5. 


\title{
A multiobjective optimization of the welding process in aluminum alloy (AA) $6063 \mathrm{T4}$ tubes used in corona rings through normal boundary intersection and multivariate techniques
}

\author{
*Eduardo Rivelino Luz, Estevão Luiz Romão, Simone Carneiro Streitenberger, Leonardo Ribeiro Mancilha, \\ Anderson Paulo de Paiva, Pedro Paulo Balestrassi \\ ${ }^{1}$ Institute of Industrial Engineering and Management, Federal University of Itajubá, Itajubá-MG, Brazil
}

*Corresponding author: $\underline{\text { eluz7777@gmail.com }}$

\begin{abstract}
The welding process in aluminum is not a simple task to carry out. Problems such as weld bead discontinuity, cracks, and lack of penetration commonly occur in this kind of process. Thus, it is extremely necessary to have an accurate specification of the parameters in order to achieve optimal values for the investigated responses. In view of this, the present paper proposes the application of a multiobjective optimization approach considering multivariate constraints based on the simultaneous confidence intervals and the elliptical region of the correlated data. Structured experiments for the welding process of aluminum alloy (AA) 6063 TA tubes used in corona rings were performed according to a face centered composite design with 4 factors, wire feed rate (Wf), arc voltage $(V)$, contact tip to the workpiece distance $(C t)$ and motor frequency $(\mathrm{Fr})$, resulting in 31 experiments. Poisson regression was applied to model the values of yield $(Y)$, dilution $(D)$, reinforcement index $(R I)$ and penetration index $(P I)$, allowing to estimate the optimal individual values with regards to the multivariate constraints. Rotated factor scores were obtained in order to replace the original data and therefore the factor multivariate square error was used as objective functions to be minimized through normal boundary intersection method. It was possible to observe that a satisfactory weld bead with large values of PI, D and Y and a small value of RI, was reached as pre specified by the manager of the process.
\end{abstract}

Keywords: Aluminum welding . Design of experiments . Multiobjective constrained optimization . Factor analysis . Simultaneous confidence intervals

\section{Introduction}

Corona rings are used to improve the performance of the insulator strings. They reduce corona discharges as well as associated audible noise level, and radio and television interference levels. Corona rings do also improve the voltage distribution along the insulator string by reducing the percentage of the voltage on the nearest unit to the power transmission line. Moreover, they also alleviate corona degradation of non-ceramic materials. They are toroidal shaped metallic rings which are fixed at the end of bushings and insulator strings. They are also called as anti-corona rings, and they are used to prevent corona discharge that occurs in high-voltage power lines. This discharge, or corona loss, is a significant issue in very high voltage power lines, causing power loss. One way to reduce corona discharge is using corona rings [1, 2]. Insulators for voltages above 132 $\mathrm{kV}$ should be equipped with corona rings as part of insulation system [3].

Constraints and better operating conditions are necessary for better efficiency and organizational effectiveness in the management of the Gas Metal Arc Welding (GMAW) process, better known as Metal Inert Gas (MIG) welding, of anti-corona protection rings. Considering a 
project of a Brazilian company, these rings are manufactured using aluminum alloy (AA) 6063 T4. Specifically for this study, a tube with diameter of $100 \mathrm{~mm}$ and thickness of $2 \mathrm{~mm}$ was used. The company manufactures other designs of anti-corona rings, with different diameters and thicknesses, but in the same material with the same characteristics and properties (AA6063 T4).

The use of aluminum is due to its weight, since it is lighter when compared with other metals, and because AA 6063 presents an electrical conductivity that satisfies the projects of companies such as the electric energy segment, consumers of this kind of product.

Among studies such as [4-7], special attention has been given to the welding of different aluminum alloys, whose usage by the energy industry is extremely intense due to good corrosion resistance, good mechanical properties and excellent electrical conductivity.

Aluminum welding is a really complex task and requires well defined parameters to present a satisfactory result, with no defects such as porosity, cracks, lack of penetration, lack of fusion, filling failures, etc. Miguel et al. in [8], established a control methodology for GMAW welding based on the response surface methodology (RSM) considering two parameters, penetration and length of the heat affected zone (HAZ). The experimental methodology for measuring both variables allowed to get better adjusted models than those obtained in other studies [8].

In [5], whose main objective was the optimization of the HAZ, RSM was exploited. This method allowed the optimization of the response function, subjected to different independent variables after modelling the influence of these variables with a minimum number of experiments. A sequential strategy was carried out in order to obtain the maximum amount of information with minimum effort. Once the variables influencing the response have been identified, the response surface was obtained and used as a reference to gradually vary the input variables that affect the response to improve its value.

Furthermore, in [9], an experimental design is presented for a GMAW welding process to maximize the amount of information with the following characteristics: response surface-based modelling (RSM) to quantify response variables of interest; statistical model selection to obtain the most informative models; statistical model checking for definitive models to ensure inference capabilities; and multiobjective optimization to identify the Pareto front of optimal solutions.

Several papers found in literature [5, 6, 9-12] use techniques such as factor analysis, normal boundary intersection (NBI) and RSM for multiobjective optimization. However, they combine NBI and multivariate mean square error (MMSE), disregarding multivariate constraints.

In view of this, the present paper is motivated and justified by the need of obtaining better technical results, elimination of welding defects, optimization of the resources and reduction of waste in the MIG welding process in aluminum alloy (AA) $6063 \mathrm{~T} 4$ tubes, $100 \mathrm{~mm}$ in diameter with a $2 \mathrm{~mm}$ wall thick. As previously discussed, this is the main raw material for manufacturing 
anti-corona protection rings, used by several companies in the electric energy segment during the assembly of medium and high voltage circuit breakers. Thus, this work proposes a new approach of the methodology developed in [13] for multiobjective optimization in the MIG welding process of corona rings, since the most important response had its range defined by the manager of the process what influenced in stablishing the range of the other correlated responses.

A face centered composite design with 4 factors, wire feed rate $\left(W_{f}\right)$, arc voltage $(V)$, contact tip to the workpiece distance $(C t)$ and motor frequency $(F r)$, resulting in 31 experiments, was used. The values of yield $(Y)$, dilution $(D)$, reinforcement index $(R I)$ and penetration index $(P I)$ was modeled, allowing to estimate the optimal individual values. Hence, the methodology presented here incorporates simultaneous confidence intervals and elliptical constraints to the multiobjective optimization problem. Poisson regression technique is also applied in order to model the squared residuals from the ordinary least square (OLS) models for the original variables and the original variables themselves.

The next sections are organized according to the following: section 2 presents a theoretical review of the main concepts applied in the present paper; section 3 illustrates the materials and methods applied; in section 4 the main findings are presented; and finally, section 5 presents a conclusion about the work.

\section{Background and literature review}

\subsection{Aluminum alloy (AA) 6063}

As discussed in [14], aluminum alloys are divided into workable alloys, i.e., those that undergo hot or cold mechanical working process, and cast alloys, i.e., where the final shape of the part is obtained by casting process. To classify workable and cast alloys, the Aluminum Association uses numerical designations that identify the class, the main alloying element, and modifications of the alloy within the class [15]. Table 1 exemplifies the designation system adopted for workable aluminum alloys. Cast aluminum alloys are classified by a similar process.

Table 1. Main series of workable aluminum alloys according to the Aluminum Association [14]

\begin{tabular}{ll}
\hline Series & \multicolumn{1}{c}{ Main alloying elements } \\
\hline 1XXX & Commercially pure aluminum $>99 \%$ purity (non-heat treatable) \\
\hline 2XXX & Copper (heat treatable) \\
\hline 3XXX & Manganese (non-heat treatable) \\
\hline 4XXX & Silicon (non-heat treatable) \\
\hline $\mathbf{5 X X X}$ & Magnesium (non-heat treatable) \\
\hline $\mathbf{6 X X X}$ & Magnesium and Silicon (heat treatable) \\
\hline $\mathbf{7 X X X}$ & Zinc (heat treatable) \\
\hline $\mathbf{8 X X X}$ & Other elements \\
\hline $\mathbf{9 X X X}$ & Not used
\end{tabular}


According to [16], 6xxx aluminum alloy has high content of $\mathrm{Mg}$ and $\mathrm{Si}$ elements, but shedding of $\alpha-(\mathrm{AlMnFeSi})$ inclusion phase will lead to uneven strength distribution and increase cracking risk [17]. The content of $\mathrm{Si}$ element is positively correlated with the probability of liquefaction at the grain boundary $[18,19]$. After welding, the heat treatment process should be used to reduce the amount of aging precipitates [20].

As defined by [21], AA 6063 is an aluminum alloy, with the elements of magnesium and silicon alloy. The Aluminum Association maintains the standard to control its composition. It generally has good mechanical properties and can be heat treated and welded. It is similar to the HE9 aluminum alloy in Britain. It is the most common alloy used for aluminum extrusion. It allows the formation of complex shapes with very smooth surfaces suitable for anodizing and is therefore popular for visible architectural applications, such as window frames, door frames, roofs and signage frames. Applications that require higher strength generally use 6061 or 6082 . The chemical composition of AA6063 is shown in Table 2.

Table 2. Chemical composition of AA6063 [21]

\begin{tabular}{cc}
\hline Elemento & \% \\
\hline $\mathrm{Al}$ & $98,05 \%$ \\
$\mathrm{Si}$ & $0,20 \%$ \\
$\mathrm{Fe}$ & $0,35 \%$ \\
$\mathrm{Cu}$ & $0,10 \%$ \\
$\mathrm{Mg}$ & $0,90 \%$ \\
$\mathrm{Mn}$ & $0,10 \%$ \\
$\mathrm{Cr}$ & $0,10 \%$ \\
$\mathrm{Zn}$ & $0,10 \%$ \\
$\mathrm{Ti}$ & $0,10 \%$ \\
\hline
\end{tabular}

\subsection{Multiobjective optimization}

Industrial processes generally involve an expressive number of goals that are expected to be optimized simultaneously. Although it is not always up to be reached, this characteristic does not need be neglected, since there is a pool of techniques available to perform a multiobjective optimization (MO) that allows the problem to be threaten in a more lifelike behavior [22]. According to [23], the multiobjective optimization is a decision-making tool capable of dealing with situations where multiple characteristics of the process need to be optimized at the same time. A generical way to describe it is shown in Eq. (1), where $a$ and $b$ ensure the solution space limitation and $h(\boldsymbol{x})$ is related to the equality constraint, whereas $g(\boldsymbol{x})$ refers to the inequality constraint. 


$$
\begin{aligned}
& \min _{x \in C} F(x)=\left[\begin{array}{c}
f_{1}(x) \\
f_{2}(x) \\
\vdots \\
f_{n}(x)
\end{array}\right], n>2, \quad \ldots(M O P) \\
& C=\{x: h(x)=0, g(x) \leq 0, a \leq x \leq b\}
\end{aligned}
$$

It is easy to infer that optimizing a scenario with multiple conflicting objectives will lead not to a single best solution, but to a set of solutions. Once there is a trade-off relationship between different characteristics of the system, one solution will be more connected with the better performance of determined system answer, while a second one will be driven to another attribute and so on [23]. This whole group of solutions is called Pareto optimal [24].

NBI method, applied in $[25,26]$, generate an even spread feasible solutions - the Pareto curve [23] -, that overcomes the deficiencies from the Least Squares method, and through which it is possible to analyze the context in a more practical and visual way [11,27]. A general manner for representing a NBI formulation is presented Eq. (2) [23], by means of a restricted nonlinear programming.

$$
\begin{gathered}
\max _{x, t} t \\
\text { s.t. } \overline{\boldsymbol{\Phi}} \boldsymbol{\beta}+D \widehat{\boldsymbol{n}}=\overline{\boldsymbol{F}}(\boldsymbol{x}) \\
h_{i}(\boldsymbol{x})=0 \\
g_{j}(\boldsymbol{x}) \leq 0 \\
a \leq \boldsymbol{x} \leq b
\end{gathered}
$$

where $\overline{\boldsymbol{\Phi}}$ indicates the normalized pay-off matrix, $\boldsymbol{\beta}$ is the vector of weights, $D$ represents a scalar that is perpendicular to the utopia line and $\overline{\boldsymbol{F}}(\boldsymbol{x})$ contemplates the vector of dimensioned objective functions [28].

The pay-off matrix $\boldsymbol{\Phi}$, as shown in Eq. (3), comes from the establishment of the individual minima for one objective function, so that this $i$-th optimal point $x_{i}^{*}$ is also applied in the remaining functions. This procedure is repeated until all the objective functions were examined. In this way, the position $\Phi_{i i}$ from all the matrix lines shows the optimal value of $f_{i}\left(x^{*}\right)$, while the remaining positions present the values of the other functions evaluated in $x_{i}^{*}$, line by line. The values from the main diagonal are then used to normalize the objective functions and this is a useful strategy when dealing with different variables scales or units [11, 23, 27, 29]. 


$$
\boldsymbol{\Phi}=\left[\begin{array}{ccccc}
f_{1}^{*}\left(x_{1}^{*}\right) & \ldots & f_{1}^{*}\left(x_{i}^{*}\right) & \ldots & f_{1}^{*}\left(x_{m}^{*}\right) \\
\vdots & \ddots & \vdots & & \vdots \\
f_{i}^{*}\left(x_{1}^{*}\right) & \ldots & f_{i}^{*}\left(x_{i}^{*}\right) & \ldots & f_{i}^{*}\left(x_{m}^{*}\right) \\
\vdots & & \vdots & \ddots & \vdots \\
f_{m}^{*}\left(x_{1}^{*}\right) & \ldots & f_{m}^{*}\left(x_{i}^{*}\right) & \ldots & f_{m}^{*}\left(x_{m}^{*}\right)
\end{array}\right]
$$

To normalize the original values from the $\boldsymbol{\Phi}$ matrix, two vectors are constructed, one containing the optimal values resulting from the individual optimization of all the objective functions and another composed by their worst possible values. The first vector is called Utopia while the second one is the Nadir and there are represented by Eq. (4) and Eq. (5), respectively [11, 30].

$$
\begin{aligned}
f^{U} & =\left[f_{1}^{*}\left(x_{1}^{*}\right), \ldots, f_{i}^{*}\left(x_{i}^{*}\right), \ldots, f_{m}^{*}\left(x_{m}^{*}\right)\right]^{T} \\
f^{N} & =\left[f_{1}^{N}, \ldots, f_{i}^{N}, \ldots, f_{m}^{N}\right]^{T}
\end{aligned}
$$

Once theses vectors are available, the Eq. (6) can be applied to generate the normalized payoff matrix $\overline{\boldsymbol{\Phi}}$ shown in Eq. (7).

$$
\begin{gathered}
\bar{f}_{i}(\boldsymbol{x})=\left[\frac{f_{i}(\boldsymbol{x})-f_{i}^{U}}{f_{i}^{N}-f_{i}^{U}}\right] \\
\overline{\boldsymbol{\Phi}}=\left[\begin{array}{ccccc}
\bar{f}_{1}^{*}\left(x_{1}^{*}\right) & \cdots & \bar{f}_{1}^{*}\left(x_{i}^{*}\right) & \ldots & \bar{f}_{1}^{*}\left(x_{m}^{*}\right) \\
\vdots & \ddots & \vdots & & \vdots \\
\bar{f}_{i}^{*}\left(x_{1}^{*}\right) & \cdots & \bar{f}_{i}^{*}\left(x_{i}^{*}\right) & \ldots & \bar{f}_{i}^{*}\left(x_{m}^{*}\right) \\
\vdots & & \vdots & \ddots & \vdots \\
\bar{f}_{m}^{*}\left(x_{1}^{*}\right) & \cdots & \bar{f}_{m}^{*}\left(x_{i}^{*}\right) & \ldots & \bar{f}_{m}^{*}\left(x_{m}^{*}\right)
\end{array}\right]
\end{gathered}
$$

where $\bar{f}_{i}(\boldsymbol{x})$ indicates the normalized version of the objective function $f_{i}(\boldsymbol{x})$.

The generic formulation presented in Eq. (2) can be simplified, leading to the formulation for bi-objective scenarios, as depicted in Eq. (8).

$$
\begin{gathered}
\min _{x} F(x)=\bar{f}_{1}(x) \\
\text { s.t. } \bar{f}_{1}(x)-\bar{f}_{2}(x)+2 \beta_{1}-1=0 \\
x \in \Omega \\
g_{j}(\boldsymbol{x}) \leq 0 \\
h_{j+1}(\boldsymbol{x})=0
\end{gathered}
$$

RSM can be applied to help on modelling and analyzing the objective function $f_{i}(\boldsymbol{x})$ capable of explaining a system's response of interest that is influenced by several variables and that is involved in the multiobjective optimization scenario. Since RSM is a type of design of experiment 
(DOE), it comprises a set of mathematical and statistical techniques that allows investigating and modelling complex problems from a relatively small group of runs [31], making it widely spread in the industry, consequence of its easy and economical way to implement [32].

Diverse applications of RSM are available in the literature, including a wide range of industrial processes. The study performed in [33] applied the RSM, among other techniques, to characterize the Ultrasonic-assisted drilling process of Aluminum 6061, that is known to be better when compared with conventional drilling, since it applies high-frequency vibrations with low amplitudes. Another study explored the squeeze casting process capability for casting AA2026 alloy, by investigating, through the RSM, the influence of squeeze pressure, die temperature and pouring temperature on surface roughness, ultimate tensile strength, and hardness [34].

Natarajan et.al. in [35] combined RSM and Desirability function approach to maximize metal removal rate while minimizing surface roughness, considering the spindle speed, feed rate and depth of cut as the cutting parameters. In [36], RSM was applied jointly with the global criterion method to find the optimal values for the parameters effective welding time, effective welding current, quenching time, and upslope time of the resistance spot welding process of the 22MnB5galvannealed steel. Saad et.al. [37], in turn, aiming to find the optimal parameter settings for the best surface roughness of the FDM printed part possible, applied different techniques such as particle swarm optimization, and symbiotic organism search, besides the response surface methodology.

Usually, a second order polynomial is sufficient to represent the problems for the response surface. Its general equation, as depicted in Eq. (9), includes the response of interest $(Y)$, the coefficients to be estimated $(\beta)$, the $l$ independent variables $\left(x_{l}\right)$, and the associated errors $(\varepsilon)[31$, 38].

$$
Y=\beta_{0}+\sum_{i=1}^{l} \beta_{i} x_{i}+\sum_{i=1}^{l} \beta_{i i} x_{i}^{2}+\sum_{i<j} \sum \beta_{i j} x_{i} x_{j}+\varepsilon
$$

OLS is the regression method used to estimate the $\beta$ coefficients [11]. The achievement of an analytical model with a high adequacy is intimately connected to quality of the process real output data collected. On behalf of it, a good experimental design must be planned so that can help guaranteeing these results through a minimal number of experiments [31].

The Central Composite Design (CCD) consists of a $2^{k}$ factorial design, $n_{c}$ central runs and $2^{k}$ axial runs as exemplified in Fig. 1 . The axial points are useful and necessary when the $2^{k}$ design is not efficient on fitting a first-order model, since through them it is possible to incorporate the quadratic terms into the model $[31,38]$. The adequacy or not of the models can be ascertained through the $R^{2}$ and $R_{a d j}^{2}$ coefficients, obtained by running an ANOVA test and also the residues 
normality analysis $[11,30,31,38]$.

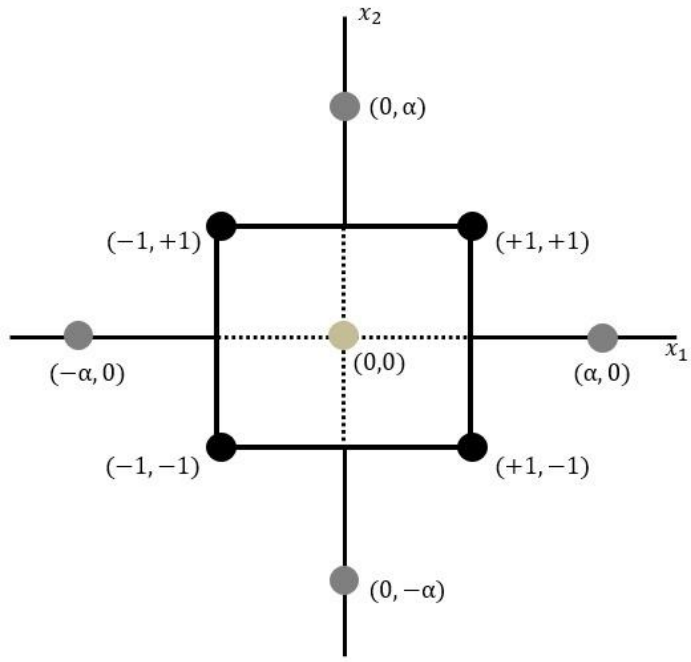

(a) $k=2$

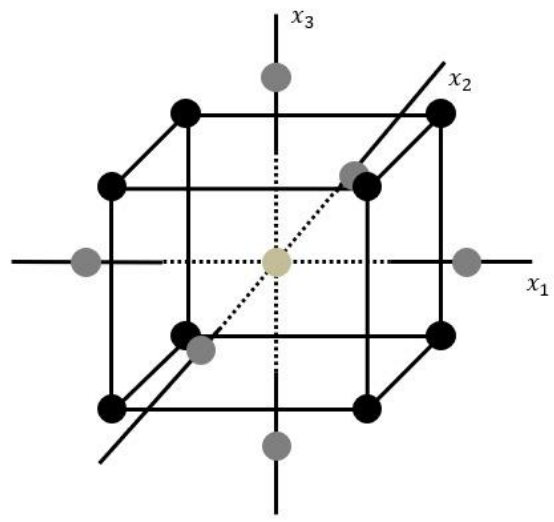

(b) $k=3$
Factorial poir Axial points Center points

Figure 1. CCD for (a) 2 and (b) 3 factors [31]

Basically, the region of operability and interest determines the value for the axial distance $\alpha$, that may vary from 1 to $\sqrt{k}$. Considering contexts where the ranges on the design variables are strict, making the region of the interest equals to the region of operability, the region for the design may be a square, a cube or a hypercube, rather than the well-known spherical region. This characterizes a variation of $\mathrm{CCD}$, called the Face-Centered Cube (CCF), since the axial points lie at the centers of the faces, as shown in Fig. 2 where a CCF for $k=3$ is illustrated. It is easy to see that, in this variation $\alpha=1$, i.e., there is no experiments located outside the cube, but, rather, at the extremes of the region. The CCF meets effectively cases of cuboidal design region and it has no limitations regarding to the number of design variables. A crucial point on determining about the suitability of a CCF relies on checking whether the axial points outside the ranges are viable, and then if they must be considered or not for the region of interest $[31,38]$.

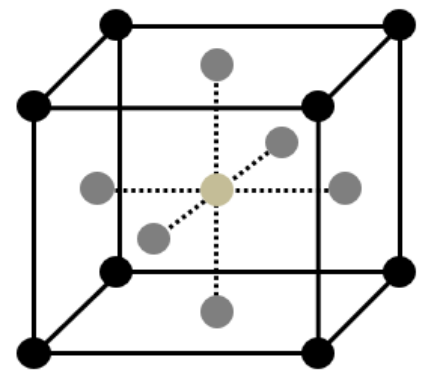

$k=3$

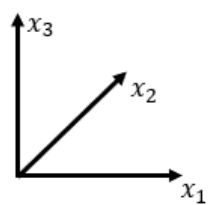

Factorial points

Axial points

Center points

Figure 2. CCF for 3 factors 


\subsection{Poisson loglinear model}

Poisson regression is an invaluable technique that should be applied when it comes to interest variables that are not normally distributed, representing a count of an event. A generalized linear model (GLM) states that a linear predictor is related to the mean $\left(\mu_{i}\right)$ for a link function $g$, that is, $\eta_{i}=g\left(\mu_{i}\right)$, where $\eta_{i}=\sum_{j=1}^{p} \beta_{j} x_{i j}$ or $\eta_{i}=\boldsymbol{x}_{i}^{\boldsymbol{T}} \boldsymbol{\beta}$ [39].

The likelihood equations for a GLM as demonstrated in [39] is shown in Eq. (10) with $j=$ $1,2, \ldots, p$, where $p$ is the number of variables.

$$
\frac{\partial \mathrm{L}(\beta)}{\partial \beta_{j}}=\sum_{i=1}^{n} \frac{\left(y_{i}-\mu_{i}\right) x_{i j}}{\operatorname{var}\left(y_{i}\right)} \frac{\partial \mu_{i}}{\partial \eta_{i}}=0
$$

For a GLM that assumes a Poisson random component and use the log link function, a link function commonly used for this type of models [40], the Poisson loglinear model could be written as shown in Eq. (11).

$$
\log \left(\mu_{i}\right)=\sum_{j=1}^{p} \beta_{j} x_{i j}=\eta_{i}
$$

This implies that $\mu_{i}=\exp \left(\eta_{i}\right)$, and consequently that $\frac{\partial \mu_{i}}{\partial \eta_{i}}=\exp \left(\eta_{i}\right)=\mu_{i}$, which means that $\operatorname{var}\left(y_{i}\right)=\mu_{i}$. Then, the likelihood equations in Eq. (10) can be simplified as in Eq. (12) with $j=1,2, \ldots, p[39]$.

$$
\sum_{j=1}^{n}\left(y_{i}-\mu_{i}\right) x_{i j}=0
$$

Once the parameters are encountered, the predictions of a Poisson loglinear model can be calculated as shown in Eq. (13) [40].

$$
\widehat{y}_{\imath}=g^{-1}\left(\boldsymbol{x}_{\boldsymbol{i}}^{T} \boldsymbol{b}\right)=\exp \left(\boldsymbol{x}_{\boldsymbol{i}}^{T} \boldsymbol{b}\right)
$$

\subsection{Multivariate analysis}

In dealing with correlated responses, it is important to consider the problem as a multivariate one [41]. This means that the variables vary concomitantly, and it is recommended to analyze them through simultaneous confidence intervals. A deeper explanation about this concept may be found in $[13,42]$.

In [42], a sophisticated way called the Bonferroni method is presented as an alternative approach to obtain these intervals as shown in Eq. (14). 


$$
\bar{x}_{p}-t_{n-1}\left(\frac{\alpha}{2 p}\right) \sqrt{\frac{S_{p p}}{n}} \leq \mu_{p} \leq \bar{x}_{p}+t_{n-1}\left(\frac{\alpha}{2 p}\right) \sqrt{\frac{S_{p p}}{n}}
$$

where the mean value of the original variables is represented by $\bar{x}_{p}$, the term $t_{n-1}\left(\frac{\alpha}{2 p}\right)$ represents the $t$ value associated to a distribution with $n-1$ degree of freedom that leads to a probability equals to $\alpha / 2 p$, where $\alpha$ is the significance level, and $p$ the number of considered components. Finally, $S_{p p}$ is the variance associated to the $p$ component and $n$ is the number of observations.

For two correlated variables it is possible to construct an ellipsoid for their means according to Eq. (15) [43]. It is worth mentioning that $\mu_{y_{i}}$ is the mean of the variables, $p$ is the number of variables being considered (in this case $p=2$, since the equation is used to construct a $2 \mathrm{D}$ ellipsoid), $n$ is the number of observations of the variables, $F$ is the statistic associated with significance level $\alpha$ and two degree of freedom ( $p$ and $n-p), \lambda_{i}$ and $e_{i j}$ represent the eigenvalues and the elements of the matrix composed of the eigenvectors, respectively, and finally $\theta$ is an angle that varies from 0 to $2 \pi$.

$$
\left[\begin{array}{l}
\mu_{y_{1}} \\
\mu_{y_{2}}
\end{array}\right]+\sqrt{\frac{p(n-1)}{n(n-p)} F_{(p, n-p)}(\alpha) \times\left[\begin{array}{cc}
\sqrt{\lambda_{1}} & 0 \\
0 & \sqrt{\lambda_{2}}
\end{array}\right] \times\left[\begin{array}{ll}
e_{11} & e_{12} \\
e_{21} & e_{22}
\end{array}\right]} \times\left[\begin{array}{c}
\cos \theta \\
\operatorname{sen} \theta
\end{array}\right]
$$

Similarly, an ellipsoid for the original data may also be constructed applying Eq. (16), which results in a larger ellipsoid than the one for the means.

$$
\left[\begin{array}{l}
\mu_{y_{1}} \\
\mu_{y_{2}}
\end{array}\right]+c \times\left[\begin{array}{ll}
e_{11} & e_{12} \\
e_{21} & e_{22}
\end{array}\right] \times\left[\begin{array}{cc}
\sqrt{\lambda_{1}} & 0 \\
0 & \sqrt{\lambda_{2}}
\end{array}\right] \times\left[\begin{array}{l}
\cos \theta \\
\operatorname{sen} \theta
\end{array}\right]
$$

It is also possible to observe the Bonferroni confidence intervals in Fig. 3 in which is depicted the green ellipsoid constructed using Eq. (15) and the blue one using Eq. (16).

Nevertheless, in some situations, it is preferrable to work with uncorrelated variables instead of the original correlated ones. Principal component analysis (PCA) and factor analysis are indicated for these cases. According to [42], factor analysis can be considered an extension of PCA, since both strategies attempt to estimate the variance-covariance matrix $(\boldsymbol{\Sigma})$ of a multivariate dataset. However, factor analysis provides a more elaborated approximation of $\boldsymbol{\Sigma}$. In addition, in PCA each principal component is written as a function of the original variables whereas, in factor analysis, each original variable is written as a function of the latent variables, that is, the factors. 


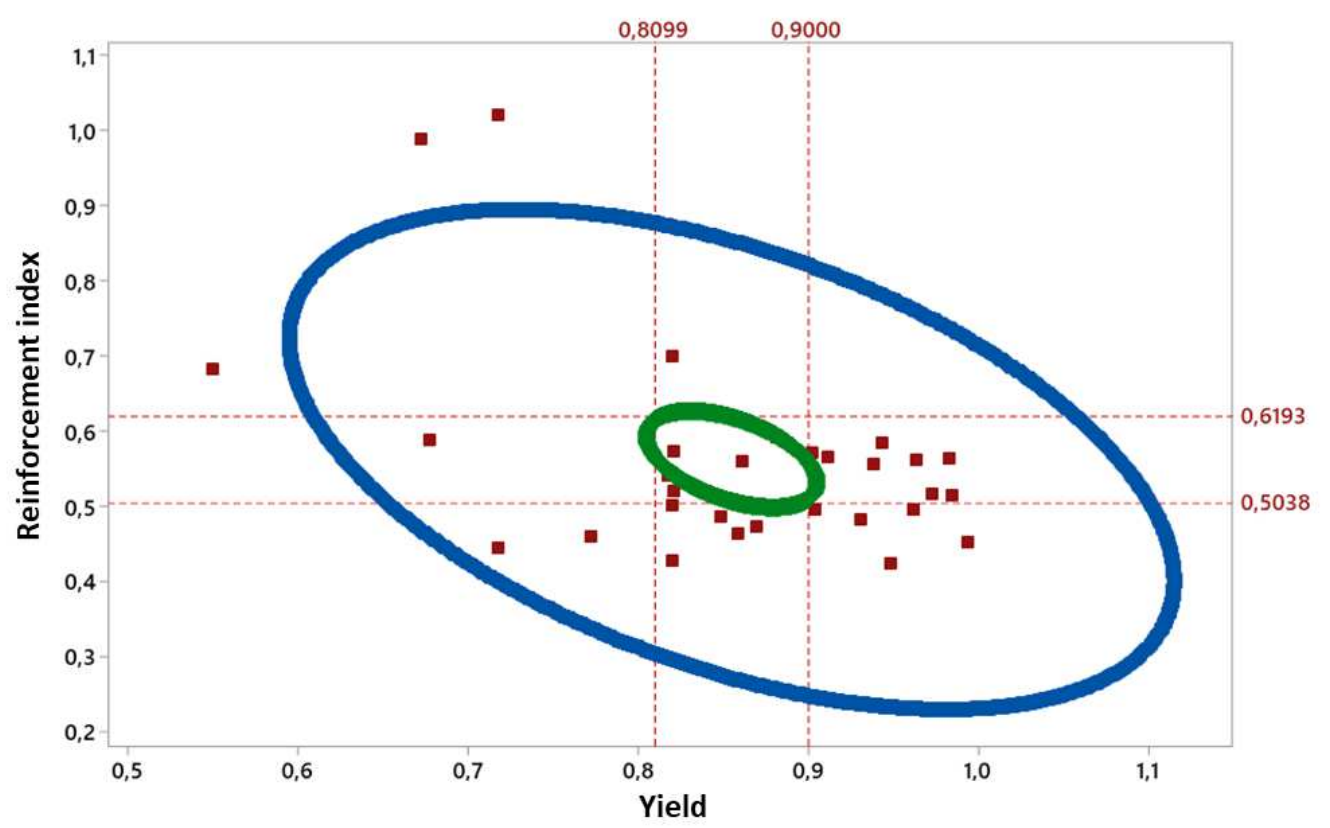

Figure 3. Ellipsoid for the mean, showing the Bonferroni intervals, and for the original data

The orthogonal factor model, in which $p$ distinct variables are well explained by $m$ factors, where $m<p$ can be observed in Eq. (17) in matrix notation. $\boldsymbol{X}$ is a random vector $(p \times 1)$ with $p$ components, $\boldsymbol{\mu}$ is its mean vector $(p \times 1)$ and $\boldsymbol{\Sigma}$ is its variance-covariance matrix $(p \times p)$. Moreover, $\boldsymbol{L}$ indicates the vector of loadings $(p \times m)$, whose values $l_{i j}$ represent the correlation of the ith variable with the jth factor, $\boldsymbol{F}$ represents the vector of unobservable variables (common factors) $(m \times 1)$, and finally, $\boldsymbol{\varepsilon}$ is the source of variation, which means the vector of errors $(p \times 1)$.

$$
\boldsymbol{X}=\boldsymbol{\mu}+\boldsymbol{L F}+\boldsymbol{\varepsilon}
$$

It is worth mentioning that $E(\boldsymbol{F})=0, \operatorname{Cov}(\boldsymbol{F})=I$ and $E(\boldsymbol{\varepsilon})=0, \operatorname{Cov}(\boldsymbol{\varepsilon})=\boldsymbol{\Psi}$, where $\boldsymbol{\Psi}$ is a diagonal matrix. In addition, the model previously shown in Eq. (X) implies that the covariance structure for $\boldsymbol{X}$ can be written as in Eq. (18) [42].

$$
\begin{aligned}
\boldsymbol{\Sigma} & =\operatorname{Cov}(\boldsymbol{X})=E(\boldsymbol{X}-\boldsymbol{\mu})(\boldsymbol{X}-\boldsymbol{\mu})^{\prime} \\
& =\boldsymbol{L} E\left(\boldsymbol{F} \boldsymbol{F}^{\prime}\right) \boldsymbol{L}^{\prime}+E\left(\boldsymbol{\varepsilon} \boldsymbol{F}^{\prime}\right) \boldsymbol{L}^{\prime}+\boldsymbol{L} E\left(\boldsymbol{F} \boldsymbol{\varepsilon}^{\prime}\right)+E\left(\boldsymbol{\varepsilon} \boldsymbol{\varepsilon}^{\prime}\right) \\
& =\boldsymbol{L} \boldsymbol{L}^{\prime}+\boldsymbol{\Psi}
\end{aligned}
$$

In view of this, it is possible to work with uncorrelated rotated factor scores instead of the original correlated variables in an optimization problem. However, in some cases, a factor explains different variables with distinct optimization direction. This conflict in the optimization direction can be overcome by using Eq. (19), which presents the factor mean square error (FMSE) developed in [44] as an extension of the multivariate mean square error (MMSE) proposed in [45]. 


$$
\operatorname{FMSE}_{\mathrm{i}}=\left[\hat{F}_{i}(\boldsymbol{x})-T_{i}\right]^{2}+\lambda_{i}
$$

It is worth mentioning that $\widehat{F}_{i}$ indicates the fitted value for the $i$-th factor, $T_{i}$ represents the target and $\lambda_{i}$ is the variance associated to the factor. The target of the $i$-th factor can be obtained through the product $\boldsymbol{Z}^{\prime} \boldsymbol{L}_{\boldsymbol{i}}$, where is the loading vector of the factor and $\boldsymbol{Z}$ is calculated subtracting the individual target of each original variable from its mean and diving this result by the standard deviation of the variable, as shown in Eq. (20).

$$
Z_{j}^{\prime}=\left(\frac{\zeta_{j}-\mu_{j}}{\sigma_{j}}\right)
$$

\section{Materials and methods}

The present paper aims to optimize the welding process of aluminum tubes, that take part in corona rings, regarding some variables such as $Y, R I, D$ and $P I$. It is important to highlight that $R I$ was obtained as the ratio between the height of the weld bead and its width. $D$ is the ration between penetration area or internal area (IA) and total area, which is defined by the sum of $I A$ and the reinforcement area or external area $(E A)$, of the weld bead. Finally, $P I$ is ratio between the penetration height and the thickness of the material being welded.

To calculate the actual deposition yield - $Y$, it was necessary to weigh 1 meter of ER4043 wire (linear mass), with $1.2 \mathrm{~mm}$ in diameter, used to calculate the total mass. Before and after the completion of each weld, the specimens were weighed, obtaining the value of the initial mass (IM), mass of the specimen before welding, and final mass $(F M)$, mass of the specimen after welding and after cleaning to remove spatter.

Some factors that possibly have great influence on the welding process were stated in Table 3 after some research in the literature $[5,8,46,47]$. Their levels were also established not only according to the values found in literature, but mainly according to some experiments performed by the authors.

Table 3. Parameters considered in the welding process and their respective levels

\begin{tabular}{cccc}
\hline Factor & Abbreviation & Level -1 & Level +1 \\
\hline Wire feed rate $(\mathrm{m} / \mathrm{min})$ & $W f$ & 3.0 & 3.4 \\
\hline Arc Voltage $(\mathrm{V})$ & $V$ & 20 & 23 \\
\hline Contact tip to the workpiece distance $(\mathrm{mm})$ & $C t$ & 8 & 16 \\
\hline Rotation frequency $(\mathrm{Hz})$ & $F r$ & 1.8 & 2.2 \\
\hline
\end{tabular}

Next, a CCF with 31 runs was applied in order to perform the experiments. The MIG welding process of the specimens was carried out with an Aristo Power 460 welding machine - 
ESAB brand - with an external wire feeder. Some devices were used to hold the torch and the part, as depicted in Fig. 4. It is possible to state that the welding process was performed in a semiautomatic way, since the torch and the part were static and a person was responsible just for triggering the torch.

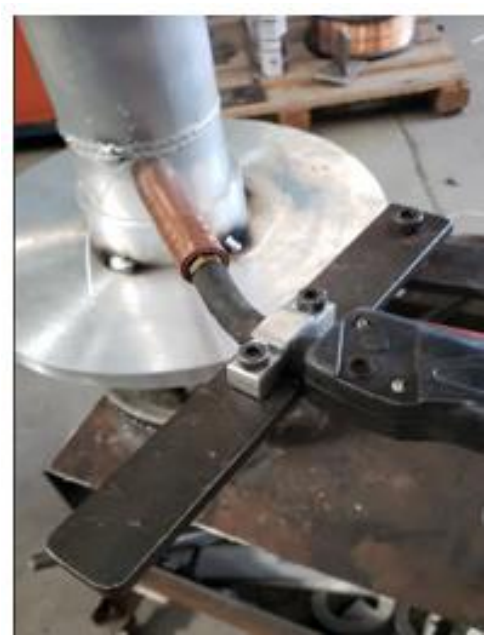

Figure 4. Semi-automatic welding process structure

The experiments were performed as homogeneous as possible, that is, using the same machine, the same welding inputs, the same person triggering the torch, and the same structure. Only the welding parameters (controllable variables) were possible to be changed.

The machine was created to weld parts that have the same profile as the object of this study. For this purpose, an aluminum plate was machined and an axis was welded to it with the inner diameter of the tube of $100 \mathrm{~mm}$, so that this tube could remain fixed during the welding process. In addition, a frequency inverter was connected to the machine's motor, in order to start the motor and control the welding speed. The rotation of the part to be welded was due to interlocking pulleys and belts that made the plate rotate. As can be sees in Fig. 4, the arm that supports the torch and a clamp, fixed the torch using allen screws. With these measures, it was possible to maintain the distance parameters and the best possible regulation for carrying out the experiments.

The specimens were welded randomly according to CCF. Next, they were cut, treated and submitted to metallographic analysis of images in the laboratories of the Federal University of Itajubá, under the supervision of specialized personnel.

Regarding the welding process, the upper and the lower parts of the tube were put over a small cylindric piece consisted of the same base metal (aluminum) aiming to hold these parts of the tube, making them concentric, allowing more accurate weld as in a bushing process. It is possible to observe the internal part of the tube in Fig. 5. 


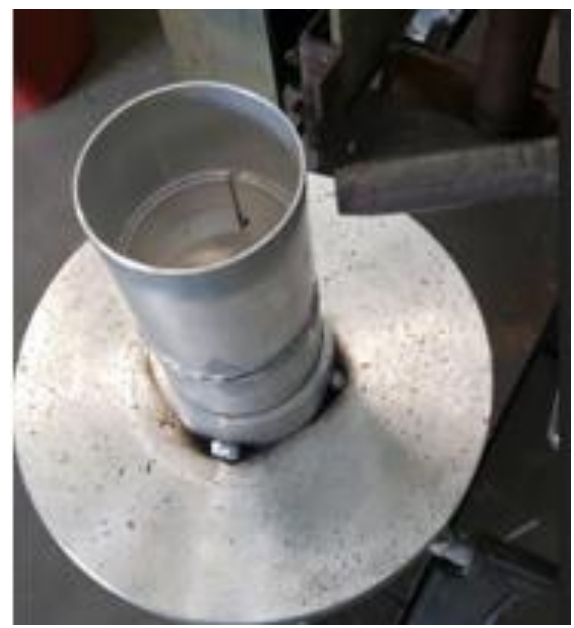

Figure 5. Inside view of the specimen and the cylindric piece

Each cylindric specimen, as depicted in Fig. 5, was cut into four quadrants that were, afterwards, subdivided into small parts. One of these, from each quadrant, was selected to go through the resin mounting process, resulting in a final mounted specimen consisting of four parts as shown in Fig. 6. Still in Fig. 6, it is possible to observe part of the welded tube and the weld bead (upper), the cylindric metal piece (lower), and an empty space between the tube and this piece. However, it is not a welding defect as it does not interfere in the construction of the corona ring.

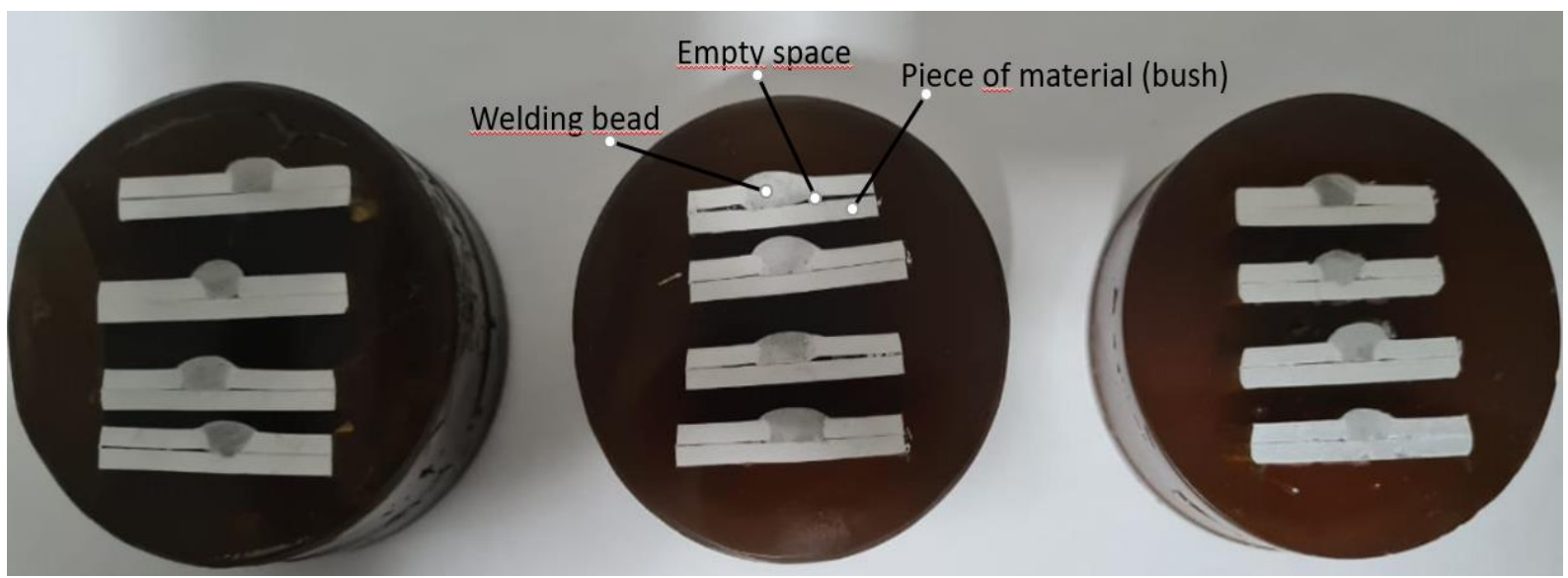

Figure 6. Specimen obtained in the runs 01,07 and 20 of the $\mathrm{CCF}$

The specimen shown in Fig. X were sanded and put in a keller solution composed of 190 $\mathrm{mL} \mathrm{H} \mathrm{H}_{2} \mathrm{O}+5 \mathrm{~mL} \mathrm{HNO}_{3}(65 \%)+3 \mathrm{~mL} \mathrm{HCl}(32 \%)+2 \mathrm{~mL} \mathrm{HF}(40 \%)$, making possible to see the area where the metal was deposited. In Fig. 7, it is possible to observe some images of the weld bead and the measurements of the penetration $(P)$, reinforcement $(R)$, internal area $(I A)$, external area $(E A)$, width $(W)$, and height $(H=R+P)$. 

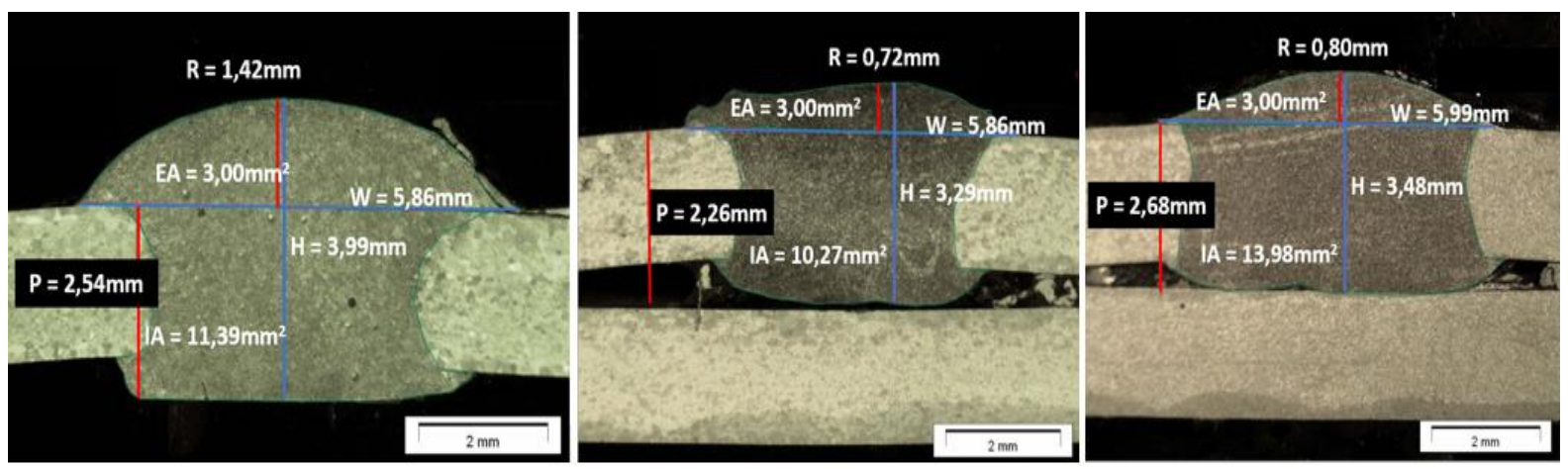

Figure 7. Images obtained from run 3, 9, and 15 of the CCF and their geometry measurements

The analysis of the results followed mainly a recent methodology published in [13]. However, an improvement was done in step G. The methodology applied in this paper is presented bellow in 9 steps.
A. Evaluate the correlation structure of the dataset
B. Perform factor analysis
C. Generate the models for all of the original responses using OLS
D. Generate full quadratic models using General Linear Models (Poisson regression) for the square residuals
E. Generate Poisson models for the original variables
F. Perform individual optimization
G. Establish the constraints based on simultaneous confidence intervals
H. Adapt the Payoff matrix
I. Apply NBI method for the factor mean square error

The next section presents the results obtained in each step of this methodology.

\section{Results}

Initially, all the data obtained through the execution of the 31 experiments are shown in Table 4, where the following abbreviations $Y, D, R I$, and $P I$ stand for yield, dilution, reinforcement index, and penetration index, respectively.

A. Evaluate the correlation structure of the dataset

The correlation structure of the original variables considered in this paper can be seen in Table 5 . In this table, the correlation values are shown associated to a p-value in italics. A p-value which is less than 0.05 indicates a significant correlation. 
Table 4. Designed experiments and the values for the investigated responses

\begin{tabular}{|c|c|c|c|c|c|c|c|c|}
\hline Run & $\begin{array}{c}W f \\
(\mathrm{~m} / \mathrm{min})\end{array}$ & $\begin{array}{c}V \\
(V)\end{array}$ & $\begin{array}{c}C t \\
(\mathbf{m m})\end{array}$ & $\begin{array}{c}\boldsymbol{F r} \\
(\boldsymbol{H z})\end{array}$ & $\begin{array}{c}Y \\
(\%)\end{array}$ & $\begin{array}{c}D \\
(\%)\end{array}$ & $\begin{array}{l}R I \\
(-)\end{array}$ & $\begin{array}{l}P I \\
(-)\end{array}$ \\
\hline 1 & 3.00 & 20.00 & 8.00 & 1.80 & 98.31 & 60.1778 & 0.5632 & 1.1363 \\
\hline 2 & 3.40 & 20.00 & 8.00 & 1.80 & 93.07 & 61.7276 & 0.4823 & 1.2363 \\
\hline 3 & 3.00 & 23.00 & 8.00 & 1.80 & 91.14 & 60.7197 & 0.5648 & 1.2588 \\
\hline 4 & 3.40 & 23.00 & 8.00 & 1.80 & 67.77 & 62.0990 & 0.5870 & 1.5913 \\
\hline 5 & 3.00 & 20.00 & 16.00 & 1.80 & 97.29 & 57.5209 & 0.5163 & 1.2913 \\
\hline 6 & 3.40 & 20.00 & 16.00 & 1.80 & 90.36 & 65.1469 & 0.4958 & 1.5525 \\
\hline 7 & 3.00 & 23.00 & 16.00 & 1.80 & 99.33 & 70.3952 & 0.4520 & 1.1963 \\
\hline 8 & 3.40 & 23.00 & 16.00 & 1.80 & 94.88 & 64.9567 & 0.4224 & 1.0775 \\
\hline 9 & 3.00 & 20.00 & 8.00 & 2.20 & 82.11 & 75.3409 & 0.5201 & 1.1975 \\
\hline 10 & 3.40 & 20.00 & 8.00 & 2.20 & 81.77 & 66.8018 & 0.5407 & 1.2563 \\
\hline 11 & 3.00 & 23.00 & 8.00 & 2.20 & 96.19 & 70.0545 & 0.4952 & 1.0863 \\
\hline 12 & 3.40 & 23.00 & 8.00 & 2.20 & 86.94 & 59.2924 & 0.4715 & 1.0500 \\
\hline 13 & 3.00 & 20.00 & 16.00 & 2.20 & 82.11 & 69.8114 & 0.5720 & 1.1825 \\
\hline 14 & 3.40 & 20.00 & 16.00 & 2.20 & 84.87 & 67.2177 & 0.4845 & 1.1413 \\
\hline 15 & 3.00 & 23.00 & 16.00 & 2.20 & 93.84 & 71.7013 & 0.5562 & 1.2238 \\
\hline 16 & 3.40 & 23.00 & 16.00 & 2.20 & 85.91 & 64.6680 & 0.4622 & 0.9988 \\
\hline 17 & 3.00 & 21.50 & 12.00 & 2.00 & 98.41 & 61.3725 & 0.5130 & 1.2452 \\
\hline 18 & 3.40 & 21.50 & 12.00 & 2.00 & 77.19 & 71.2751 & 0.4594 & 1.2676 \\
\hline 19 & 3.20 & 20.00 & 12.00 & 2.00 & 71.76 & 71.4314 & 1.0211 & 1.4963 \\
\hline 20 & 3.20 & 23.00 & 12.00 & 2.00 & 82.01 & 69.5993 & 0.6993 & 1.3200 \\
\hline 21 & 3.20 & 21.50 & 8.00 & 2.00 & 71.76 & 61.9859 & 0.4433 & 1.1963 \\
\hline 22 & 3.20 & 21.50 & 16.00 & 2.00 & 82.01 & 73.6002 & 0.6248 & 1.3425 \\
\hline 23 & 3.20 & 21.50 & 12.00 & 1.80 & 67.20 & 58.9240 & 0.9889 & 1.2800 \\
\hline 24 & 3.20 & 21.50 & 12.00 & 2.20 & 54.99 & 70.9638 & 0.6815 & 1.3763 \\
\hline 25 & 3.20 & 21.50 & 12.00 & 2.00 & 88.16 & 70.6565 & 0.5909 & 1.1825 \\
\hline 26 & 3.20 & 21.50 & 12.00 & 2.00 & 86.11 & 69.0965 & 0.5590 & 1.1338 \\
\hline 27 & 3.20 & 21.50 & 12.00 & 2.00 & 94.31 & 65.8828 & 0.5841 & 1.0950 \\
\hline 28 & 3.20 & 21.50 & 12.00 & 2.00 & 96.36 & 61.7419 & 0.5603 & 0.9525 \\
\hline 29 & 3.20 & 21.50 & 12.00 & 2.00 & 90.21 & 65.7591 & 0.5710 & 1.1525 \\
\hline 30 & 3.20 & 21.50 & 12.00 & 2.00 & 82.01 & 67.8660 & 0.4264 & 1.2163 \\
\hline 31 & 3.20 & 21.50 & 12.00 & 2.00 & 82.01 & 64.0694 & 0.4997 & 1.1913 \\
\hline
\end{tabular}

Table 5. Correlation matrix of the original variables

\begin{tabular}{cccc}
\hline & $\boldsymbol{Y}$ & $\boldsymbol{D}$ & $\boldsymbol{R I}$ \\
\hline $\boldsymbol{D}$ & -0.201 & & \\
& 0.278 & & \\
\hline $\boldsymbol{R} \boldsymbol{P I}$ & -0.484 & 0.077 & \\
& 0.006 & 0.682 & 0.417 \\
& -0.494 & 0.123 & 0.020 \\
\hline
\end{tabular}




\section{B. Perform factor analysis}

Factor analysis was performed and the rotated scores of the factors were stored. It is important to highlight that varimax rotation was used here since it presents satisfactory results as shown in [48]. Table 6 shows the values scores considering 3 factors and 4 original variables. These factors are able to explain $88.2 \%$ of the variability of the data.

Table 6. Rotated factor scores for each designed experiment

\begin{tabular}{cccccccc}
\hline $\boldsymbol{R u n}$ & $\boldsymbol{W} \boldsymbol{f}$ & $\boldsymbol{V}$ & $\boldsymbol{C} \boldsymbol{T}$ & $\boldsymbol{F r}$ & $\boldsymbol{F}_{\boldsymbol{1}}$ & $\boldsymbol{F}_{\mathbf{2}}$ & $\boldsymbol{F}_{\mathbf{3}}$ \\
\hline 1 & 3.00 & 20.00 & 8.00 & 1.80 & -0.8286 & -0.0590 & -1.2966 \\
\hline 2 & 3.40 & 20.00 & 8.00 & 1.80 & 0.1592 & -0.7504 & -0.9590 \\
\hline 3 & 3.00 & 23.00 & 8.00 & 1.80 & 0.1672 & -0.1648 & -1.2167 \\
\hline 4 & 3.40 & 23.00 & 8.00 & 1.80 & 2.9331 & -0.2198 & -0.9940 \\
\hline 5 & 3.00 & 20.00 & 16.00 & 1.80 & 0.3945 & -0.7208 & -1.9338 \\
\hline 6 & 3.40 & 20.00 & 16.00 & 1.80 & 2.2376 & -1.4006 & -0.4800 \\
\hline 7 & 3.00 & 23.00 & 16.00 & 1.80 & -0.3512 & -1.1151 & 0.8347 \\
\hline 8 & 3.40 & 23.00 & 16.00 & 1.80 & -0.8463 & -0.8566 & -0.1451 \\
\hline 9 & 3.00 & 20.00 & 8.00 & 2.20 & -0.1320 & -0.2234 & 1.9763 \\
\hline 10 & 3.40 & 20.00 & 8.00 & 2.20 & 0.3633 & -0.1339 & 0.1471 \\
\hline 11 & 3.00 & 23.00 & 8.00 & 2.20 & -1.0997 & -0.4504 & 0.8533 \\
\hline 12 & 3.40 & 23.00 & 8.00 & 2.20 & -0.8384 & -0.1763 & -1.2577 \\
\hline 13 & 3.00 & 20.00 & 16.00 & 2.20 & -0.2681 & 0.2309 & 0.8091 \\
\hline 14 & 3.40 & 20.00 & 16.00 & 2.20 & -0.3477 & -0.3315 & 0.3285 \\
\hline 15 & 3.00 & 23.00 & 16.00 & 2.20 & -0.3085 & -0.3151 & 1.0733 \\
\hline 16 & 3.40 & 23.00 & 16.00 & 2.20 & -1.2200 & -0.1377 & -0.0859 \\
\hline 17 & 3.00 & 21.50 & 12.00 & 2.00 & -0.0007 & -0.6969 & -1.1056 \\
\hline 18 & 3.40 & 21.50 & 12.00 & 2.00 & 0.6949 & -0.6539 & 1.1560 \\
\hline 19 & 3.20 & 20.00 & 12.00 & 2.00 & 0.9165 & 2.8736 & 0.7319 \\
\hline 20 & 3.20 & 23.00 & 12.00 & 2.00 & 0.3239 & 0.7898 & 0.5842 \\
\hline 21 & 3.20 & 21.50 & 8.00 & 2.00 & 0.5736 & -0.3561 & -0.6602 \\
\hline 22 & 3.20 & 21.50 & 16.00 & 2.00 & 0.5947 & 0.1718 & 1.4411 \\
\hline 23 & 3.20 & 21.50 & 12.00 & 1.80 & -0.0929 & 3.4257 & -1.6378 \\
\hline 24 & 3.20 & 21.50 & 12.00 & 2.20 & 1.4600 & 1.2374 & 1.0764 \\
\hline 25 & 3.20 & 21.50 & 12.00 & 2.00 & -0.4973 & 0.1935 & 0.9194 \\
\hline 26 & 3.20 & 21.50 & 12.00 & 2.00 & -0.6555 & 0.1601 & 0.6704 \\
\hline 27 & 3.20 & 21.50 & 12.00 & 2.00 & -1.1457 & 0.2431 & -0.0551 \\
\hline 28 & 3.20 & 21.50 & 12.00 & 2.00 & -2.0142 & 0.4141 & -0.8084 \\
\hline 29 & 3.20 & 21.50 & 12.00 & 2.00 & -0.6161 & 0.1197 & -0.0815 \\
\hline 30 & 3.20 & 21.50 & 12.00 & 2.00 & 0.3661 & -0.8557 & 0.4638 \\
\hline 31 & 3.20 & 21.50 & 12.00 & 2.00 & 0.0783 & -0.2419 & -0.3480 \\
\hline & & & & & & & \\
\hline
\end{tabular}

C. Generate models for all of the original responses using OLS

The original variables and the rotated scores of the factors were initially modeled through OLS method and they had their residuals stored and squared to be used in step D. 
D. Generate full quadratic models using General Linear Models (Poisson regression) for the square residuals

Poisson regression was used in the present step to model the 4 sets of square residuals from step C (each set corresponds to the residuals obtained on the initial model for each original variable). The fitted value $(\hat{e})$ was stored, and the weight, $W=1 / \hat{e}^{2}$, was calculated.

E. Generate Poisson models for the original variables

Poisson models for the original variables weighted by $W$ were obtained. Some variables did not present good values for $R^{2}, R^{2}$ adj, and $R^{2}$ pred in the first interaction of the method. Thus, the steps C and D had to be repeated. These models are presented in equations from Eq. (21) to Eq. (24).

$$
\begin{aligned}
& \mathrm{Y}=\exp \left(\mathrm{Y}^{\prime}\right) \\
& Y^{\prime}=-0.1885-0.03875 \times W f+0.01604 \times V-0.00084 \times C t-0.03980 \times F r \\
& +0.1159 \times W f^{2}-0.0377 \times V^{2}-0.0129 \times C t^{2}+0.0251 \times F r^{2} \\
& +0.00042 \times W f \times V+0.00106 \times W f \times C t-0.00577 \times W f \times F r \\
& +0.0108 \times V \times C t+0.0159 \times V \times F r-0.0102 \times C t \times F r \\
& R^{2}=93.66 \% \\
& R_{a d j}^{2}=89.59 \% \\
& \mathrm{D}=\exp \left(D^{\prime}\right) \\
& D^{\prime}=4.1765-0.0301 \times W f+0.069 \times F r-0.0415 \times W f \times F r \\
& R^{2}=95.77 \% \\
& R_{a d j}^{2}=81.58 \% \\
& \mathrm{RI}=\exp \left(R I^{\prime}\right) \\
& R I^{\prime}=-0.45577-0.0437 \times W f-0.0319 \times V-0.0145 \times C t+0.0042 \times F r \\
& -0.3150 \times W f^{2}+0.1186 \times V^{2}-0.0780 \times C t^{2}+0.0474 \times F r^{2} \\
& -0.0025 \times W f \times V-0.03396 \times W f \times C t-0.0124 \times W f \times F r-0.0005 \times V \times C t \\
& +0.0092 \times V \times F r+0.0390 \times C t \times F r \\
& R^{2}=99.93 \% \\
& R_{a d j}^{2}=99.90 \% \\
& \mathrm{PI}=\exp \left(P I^{\prime}\right) \\
& P I^{\prime}=-0.1865-0.0017 \times W f-0.0178 \times V+0.01946 \times C t-0.0644 \times F r \\
& -0.0310 \times W f^{2}-0.0292 \times V^{2}+0.0144 \times C t^{2}-0.0103 \times F r^{2} \\
& +0.0113 \times W f \times V-0.0216 \times W f \times C t-0.0604 \times W f \times F r \\
& -0.044662 \times V \times C t-0.0357 \times V \times F r+0.0218 \times C t \times F r \\
& R^{2}=99.99 \% \\
& R_{a d j}^{2}=99.99 \%
\end{aligned}
$$

\section{F. Perform individual optimization}

With the models for the original variables, it is possible to perform the individual optimization for them. It is important to highlight that $Y, D$ and $P I$ are variables to be maximized whereas the $R I$ is 
to be minimized, since the reinforcement is removed from the final structure. In view of this, the payoff matrix shown in Table 7 was constructed.

Table 7. Payoff matrix considering individual optimization

\begin{tabular}{ccccc}
\hline Response & \multicolumn{4}{c}{ Payoff Matrix } \\
\hline$Y$ & 100.00 & 95.81 & 90.52 & 89.41 \\
\hline$D$ & 61.1235 & 74.8885 & 62.6405 & 61.5592 \\
\hline$R I$ & 0.5045 & 0.5143 & 0.3864 & 0.5087 \\
\hline$P I$ & 1.2367 & 1.2274 & 1.2904 & 1.5118 \\
\hline
\end{tabular}

G. Establish the constraints based on simultaneous confidence intervals

At this point it is important to perform some multivariate analyzes. Initially, the ellipsoids for the means of each pair of significantly correlated variables were generated using Eq. (15). These ellipsoids and the Bonferroni intervals are shown in Fig. 8 and Fig. 9. However, unlikely the previous article where this methodology was published, a range for the most important variable was established here. $P I$ was chosen as the most relevant variable, since the larger the penetration the better the quality of the final product. A range from 1.19 to 1.25 was defined by specialists, and therefore all the other variables had to vary according to this range, since they are correlated. Hence, the constraints to the variation of the original variables are the variation established as the intersection of the green and yellow lines in Fig. 8 and Fig. 9, and these intersections are highlighted in red on both axes.

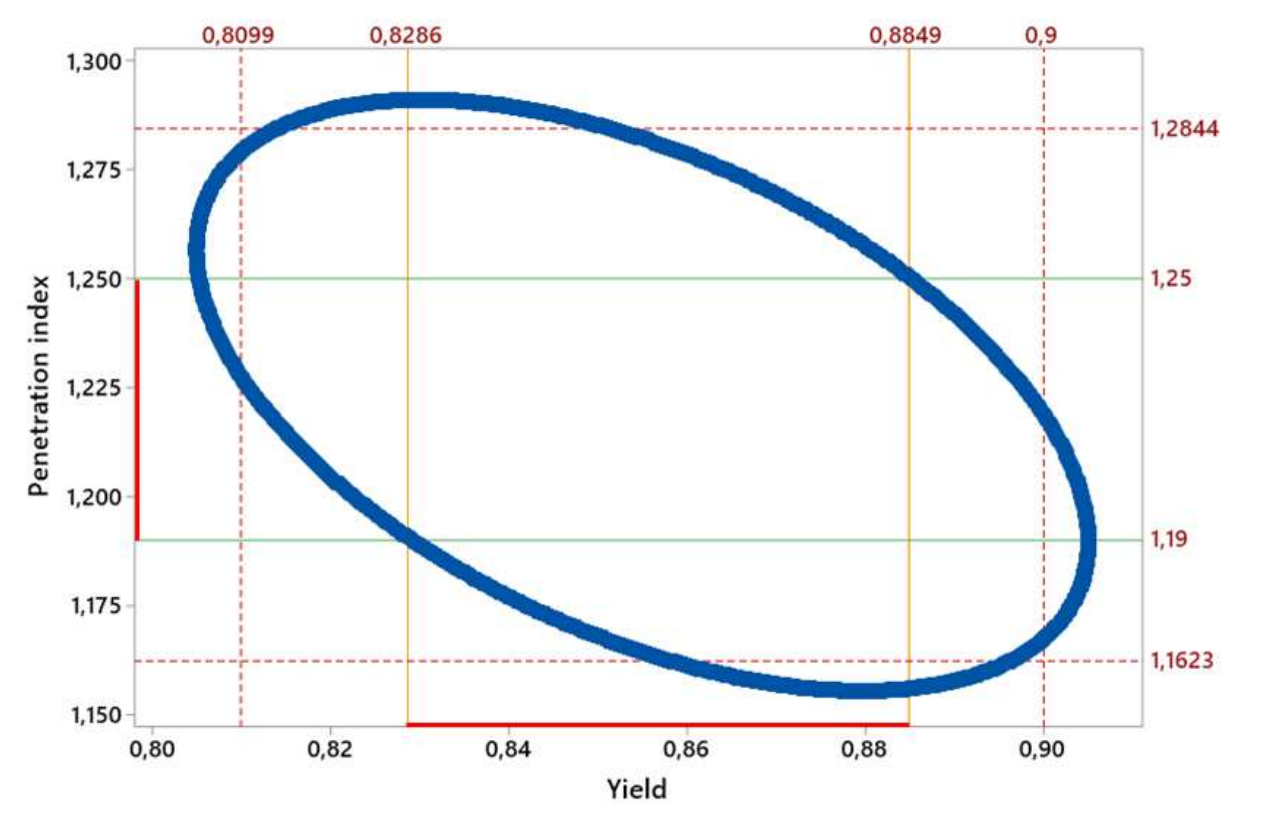

Figure 8. Elliptical region for penetration index and yield means with constraints 


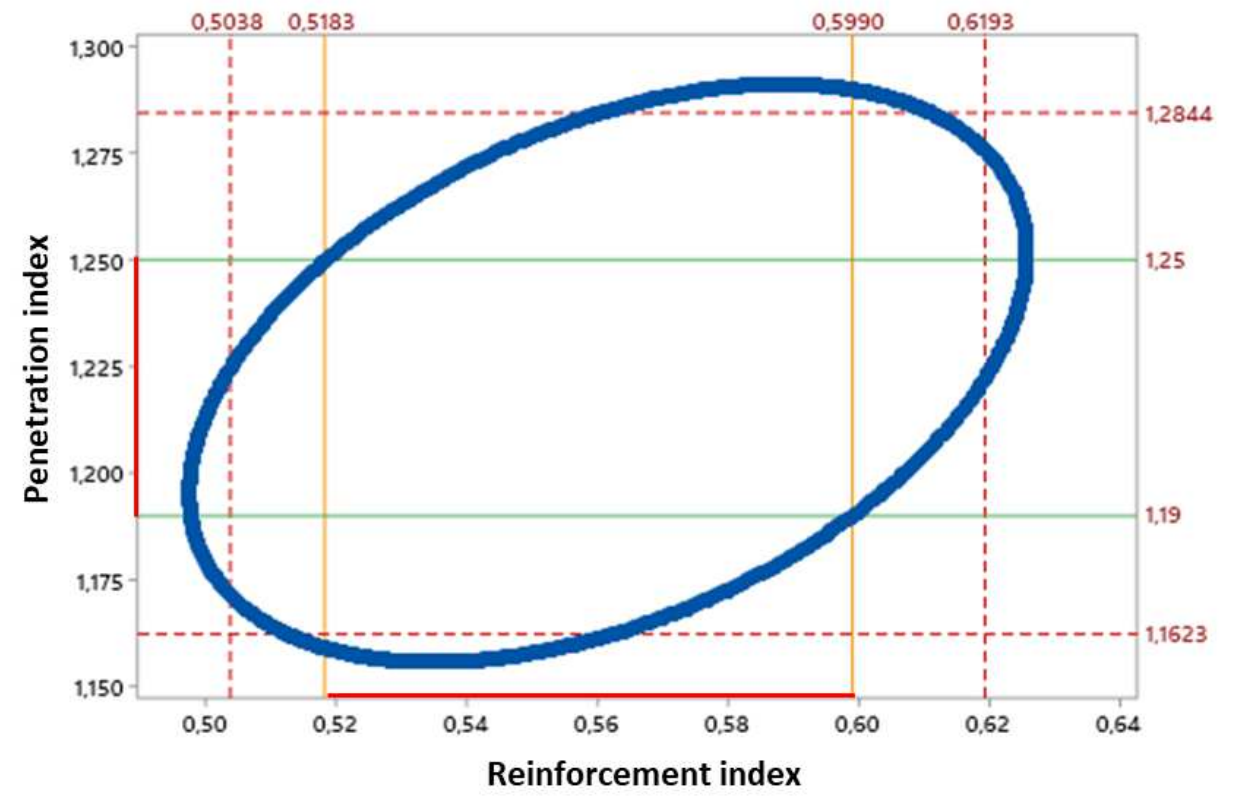

Figure 9. Elliptical region for penetration index and reinforcement index means with constraints

\section{H. Adapt the Payoff matrix}

In order to adapt the payoff matrix, an elliptical constraint was set according to Eq. (25) in addition, to the constraints established in step G. The adapted Payoff matrix can be seen in Table 8 .

$$
(\widehat{Y}-M)^{T} \Sigma^{-1}(\widehat{Y}-M) \leq \chi_{1-\alpha, p}^{2}
$$

Table 8. Adapted Payoff matrix considering elliptical constraints and Bonferroni intervals constraints

\begin{tabular}{ccccc}
\hline Response & \multicolumn{4}{c}{ Payoff Matrix } \\
\hline$Y$ & 0.8729 & 0.8286 & 0.8464 & 0.8729 \\
\hline$D$ & 62.4427 & 64.9201 & 64.3064 & 62.4427 \\
\hline$R I$ & 0.5183 & 0.5183 & 0.5183 & 0.5183 \\
\hline$P I$ & 1.2500 & 1.1900 & 1.1953 & 1.2500 \\
\hline
\end{tabular}

I. Apply NBI method for the factor mean square errors

Finally, the factor's targets were defined according to Eq. (19) and Eq. (20), and therefore the FMSE functions for the three rotated score of the factors were modeled. Matrix NBI method was applied, since 3 functions is being considered. A simplex lattice mixture design, with degree of lattice 10, was applied to generate the matrix containing 70 distinct combinations of weights ranged from 0.00001 to 0.99998 to be used in the NBI.

All the objective functions are to be minimized, since all of them are the FMSE values for the three factors. The results are summarized in Table 9 and Table 10. 
Table 9. Results of the NBI method part I

\begin{tabular}{|c|c|c|c|c|c|c|c|c|c|c|}
\hline Run & $w_{1}$ & $w_{2}$ & $w_{3}$ & FMSE1 & FMSE2 & FMSE3 & $Y$ & $D$ & $R I$ & $P I$ \\
\hline 1 & 1.00 & 0.00 & 0.00 & 1.2615 & 1.4412 & 1.0308 & 83.99 & 63.7328 & 0.5796 & 1.2310 \\
\hline 2 & 90 & .10 & 0.00 & 644 & & & 83.61 & 63.6256 & 0.5978 & 1.2400 \\
\hline 3 & 0.90 & 0.00 & 0.10 & 2633 & 370 & .0300 & 84.14 & 63.6504 & 0.5789 & 1.2326 \\
\hline 4 & 0.80 & 0.20 & 0.00 & 1.2673 & 1.4012 & 1.0384 & 83.96 & 63.4573 & 0.5986 & 1.2377 \\
\hline 5 & 0.80 & 0.10 & 0.10 & 1.2662 & 1.4170 & 1.0338 & 84.21 & 63.7872 & 0.5692 & 1.2258 \\
\hline 6 & 0.80 & 0.00 & 0.20 & 1.2650 & & 1.0293 & 84.22 & 63.5451 & 0.5811 & 1.2356 \\
\hline 7 & 0.70 & 0.30 & 0.00 & 1.2702 & & 1.0422 & 83.97 & 63.4347 & 0.5967 & 1.2374 \\
\hline 8 & 0.70 & 0.20 & 0.10 & 1.2691 & 1.3971 & 1.0376 & 84.02 & 63.4172 & 0.5966 & 1.2380 \\
\hline 9 & 0.70 & 0.10 & 0.20 & 1.2679 & 1.4128 & 1.0331 & 84.30 & 63.7469 & 0.5680 & 1.2267 \\
\hline 10 & 0.70 & 0.00 & 0.30 & 1.2668 & 1.4286 & 1.0285 & 84.31 & 63.4791 & 0.5810 & 1.2371 \\
\hline 11 & 0.60 & 0.40 & 0.00 & 1.2732 & & & 84.00 & 63.3966 & 0.5978 & 1.2373 \\
\hline 12 & 0.60 & 0.30 & 0.10 & 1.2720 & 1.3771 & 1.0414 & 84.03 & 63.3887 & 0.5967 & 1.2378 \\
\hline 13 & 0.60 & 0.20 & 0.20 & 709 & & & 84.07 & 63.3738 & 0.5957 & 1.2385 \\
\hline 14 & 0.60 & 0.10 & 0.30 & 1.2697 & 1.4087 & 1.0323 & 83.92 & 63.6857 & 0.5765 & 1.2348 \\
\hline 15 & 0.60 & 0.00 & 0.40 & 1.2686 & & 1.0278 & 84.38 & 63.4108 & 0.5814 & 1.2388 \\
\hline 16 & 0.50 & 0.50 & 0.00 & 1.2761 & & 1.0498 & 83.20 & 63.7125 & 0.5984 & 1.2449 \\
\hline 17 & 0.50 & 0.40 & 0.10 & 1.2749 & & 1.0452 & 84.04 & 63.3579 & 0.5967 & 1.2377 \\
\hline 18 & 0.50 & 0.30 & 0.20 & 1.2738 & & & 84.08 & 63.3406 & 0.5974 & 1.2382 \\
\hline 19 & 0.50 & 0.20 & 0.30 & 1.2726 & 1.3887 & 1.0361 & 84.13 & 63.3276 & 0.5955 & 1.2390 \\
\hline 20 & 0.50 & 0.10 & 0.40 & 1.2715 & & 1.0316 & 84.47 & 63.5844 & 0.5689 & 1.2322 \\
\hline 21 & 0.50 & 0.00 & 0.50 & 1.2703 & & 1.0270 & 84.45 & 63.3349 & 0.5825 & 1.2406 \\
\hline 22 & 0.40 & 0.60 & 0.00 & 2790 & & 1.05 & 83.12 & 63.7241 & 0.5978 & 1.2464 \\
\hline 23 & 0.40 & 0.50 & 0.10 & 1.2778 & 1.3372 & 1.0491 & 83.20 & 63.6974 & 0.5955 & 1.2450 \\
\hline 24 & 0.40 & 0.40 & 0.20 & 1.2767 & 530 & 1.04 & 84.09 & 63.3181 & 0.5960 & 1.2380 \\
\hline 25 & 0.40 & 0.30 & 0.30 & 1.2755 & 1.3688 & 1.0399 & 84.14 & 63.2945 & 0.5978 & 1.2386 \\
\hline 26 & 0.40 & 0.20 & 0.40 & 1.2744 & & 1.0354 & 84.18 & 63.2883 & 0.5942 & 1.2395 \\
\hline 27 & 0.40 & 0.10 & 0.50 & 1.2733 & 1.4003 & 1.0308 & 84.55 & 63.5246 & 0.5686 & 1.2340 \\
\hline 28 & 0.40 & 0.00 & 0.60 & 1.2721 & & 1.0263 & 84.49 & 63.2472 & 0.5851 & 1.2424 \\
\hline 29 & 0.30 & 0.70 & 0.00 & 1.2819 & 1.3015 & 1.0574 & 83.06 & 63.7348 & 0.5990 & 1.2486 \\
\hline 30 & 0.30 & 0.60 & 0.10 & 1.2808 & 1.3172 & 1.0529 & 83.12 & 63.7080 & 0.5951 & 1.2466 \\
\hline 31 & 0.30 & 0.50 & 0.20 & 1.2796 & 1.3330 & 1.0483 & 83.20 & 63.6811 & 0.5954 & 1.2459 \\
\hline 32 & 0.30 & 0.40 & 0.30 & 1.2785 & 1.3488 & 1.0438 & 84.13 & 63.2779 & 0.5955 & 1.2384 \\
\hline 33 & 0.30 & 0.30 & 0.40 & 1.2773 & 1.3646 & 1.0392 & 84.18 & 63.2520 & 0.5976 & 1.2390 \\
\hline 34 & 0.30 & 0.20 & 0.50 & 1.2762 & 1.3804 & 1.0346 & 84.23 & 63.2340 & 0.5957 & 1.2400 \\
\hline 35 & 0.30 & 0.10 & 0.60 & 1.2750 & 1.3961 & 1.0301 & 84.63 & 63.4625 & 0.5685 & 1.2359 \\
\hline
\end{tabular}

Table 10. Results of the NBI method Part II

\begin{tabular}{ccccccccccc}
\hline Run & $\boldsymbol{w}_{\boldsymbol{1}}$ & $\boldsymbol{w}_{\mathbf{2}}$ & $\boldsymbol{w}_{\mathbf{3}}$ & $\boldsymbol{F M S E}_{\boldsymbol{1}}$ & $\boldsymbol{F M S E}_{\boldsymbol{2}}$ & $\boldsymbol{F M S E}_{3}$ & $\boldsymbol{Y}$ & $\boldsymbol{D}$ & $\boldsymbol{R I}$ & $\boldsymbol{P I}$ \\
\hline 36 & 0.30 & 0.00 & 0.70 & 1.2739 & 1.4119 & 1.0255 & 84.53 & 63.1611 & 0.5879 & 1.2439 \\
\hline 37 & 0.20 & 0.80 & 0.00 & 1.2848 & 1.2815 & 1.0612 & 82.99 & 63.7352 & 0.5947 & 1.2498 \\
\hline 38 & 0.20 & 0.70 & 0.10 & 1.2837 & 1.2973 & 1.0567 & 83.06 & 63.7204 & 0.5990 & 1.2495 \\
\hline 39 & 0.20 & 0.60 & 0.20 & 1.2825 & 1.3131 & 1.0521 & 83.11 & 63.6927 & 0.5961 & 1.2477
\end{tabular}




\begin{tabular}{|c|c|c|c|c|c|c|c|c|c|c|}
\hline 40 & 20 & 50 & .30 & & & & 33.24 & & & \\
\hline 41 & 20 & 40 & .40 & 2802 & 3446 & & 4.18 & & 52 & .2388 \\
\hline 42 & 0 & 30 & .50 & 2791 & 3604 & & 4.23 & & & .2394 \\
\hline 43 & 20 & .20 & .60 & 779 & 762 & & 4.68 & & .5569 & 2271 \\
\hline 44 & 20 & 10 & 0.70 & 2768 & 3920 & & 84.70 & 3.3987 & .5686 & .2378 \\
\hline 45 & 20 & .00 & .80 & 2756 & 4077 & 48 & 34.57 & 33 & .5911 & .2450 \\
\hline 46 & 10 & 90 & 00 & 2877 & 2616 & & 84.67 & 3.4698 & 0.5472 & 1.2338 \\
\hline 47 & 10 & .80 & 0.10 & .28 & 73 & & 82.99 & 171 & 0.5916 & 1.2500 \\
\hline 48 & & 70 & 20 & 2854 & & & 3.04 & & & .2500 \\
\hline 49 & 10 & .60 & 0.30 & 2843 & .3090 & 1.0514 & 84.59 & 63.4800 & 0.5581 & 1.2336 \\
\hline 50 & & 50 & & 1 & 17 & & 34.82 & & & .2152 \\
\hline 51 & 10 & .40 & 50 & 2820 & 1.3404 & 1.0423 & 84.22 & 63.1999 & 0.5945 & 1.2392 \\
\hline 52 & & 30 & 60 & 2808 & 3562 & & 84.28 & & & .2398 \\
\hline 53 & & 20 & 70 & 2797 & 3720 & & 84.77 & & & 1.2285 \\
\hline 54 & & 10 & 0.80 & 2786 & 78 & & 84.77 & 329 & 0.5688 & 1.2398 \\
\hline 55 & & .00 & & 2774 & 36 & & 84.64 & & & .2461 \\
\hline 56 & 00 & 1.00 & 0.00 & 2906 & .2416 & 1.06 & 84.95 & 63.3446 & 347 & 1.2387 \\
\hline 57 & 00 & .90 & & 2895 & 2574 & 1.0 & 84.78 & 63 & 140 & 1.2344 \\
\hline 58 & 00 & .80 & 0.20 & .2883 & .2732 & & 83.01 & 63.6991 & 0.5877 & 1.2500 \\
\hline 59 & 0.00 & 0.70 & & 2872 & 89 & & 83.04 & 63.6846 & & 1.2500 \\
\hline 60 & 0.00 & 0.60 & 0.40 & 2861 & .3047 & 1.0506 & 83.10 & 63.6644 & 0.5988 & 1.2500 \\
\hline 61 & 0.00 & 0.50 & & 1.2849 & 1.3204 & & 84.90 & 63.8 & 0.5369 & 1.2131 \\
\hline 62 & 0.00 & 0.40 & 0.60 & .2838 & .3363 & 1.0415 & 84.26 & 63.1 & 949 & 1.2396 \\
\hline 63 & & 0.30 & & & & & 84.71 & & 0.5639 & 1.2368 \\
\hline 64 & 0.00 & 0.20 & 0.80 & 1.2815 & 1.3678 & 1.0324 & 84.86 & 63.5575 & 0.5555 & 1.2309 \\
\hline 65 & 0.00 & 0.10 & & 1.2803 & & & 84.83 & 63.2646 & 0.5694 & 1.2417 \\
\hline 66 & 0.00 & 0.00 & 1.00 & 1.2792 & 1.3994 & 1.0233 & 85.11 & 63.3842 & 0.5590 & 1.2402 \\
\hline 67 & 0.33 & 0.33 & 0.33 & 1.2771 & 1.3607 & & 84.14 & 63.2831 & 0.5954 & 1.2387 \\
\hline 68 & 0.67 & 0.17 & 0.17 & 1.2693 & 1.4009 & 1.0359 & 84.06 & 63.4017 & 0.5949 & 1.2383 \\
\hline 69 & 0.17 & 0.67 & 0.17 & 1.2839 & 1.3012 & 1.0549 & 83.07 & 63.7073 & 0.5990 & 1.2494 \\
\hline 70 & 0.11 & 0.17 & & 1.2781 & & 1.0321 & 84.73 & 63.5374 & 0.5610 & 1.2324 \\
\hline
\end{tabular}

The values of the factors for each combination of weights were normalized subtracting the utopia and dividing the result by the difference between nadir and utopia. The plot of normalized factors and their respective weights can be seen in Fig. 10.

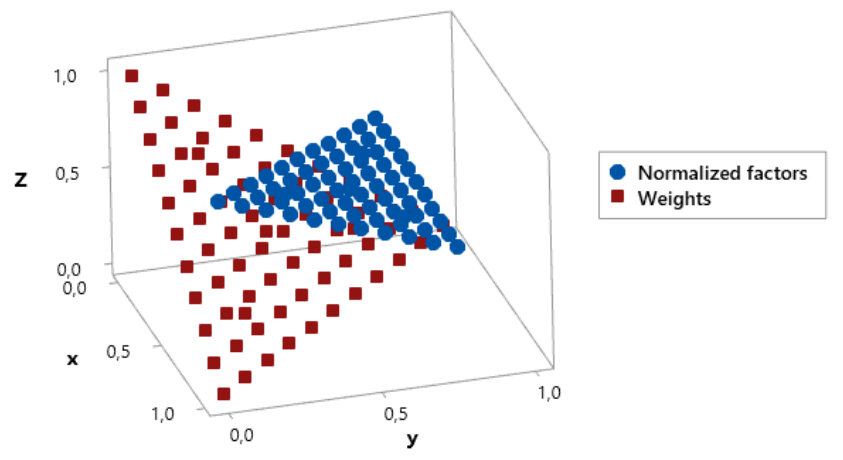

Figure 10. 3D scatterplot of the normalized factors and weights 
In order to choose the best combination of weights, it was applied the ratio $(R)$ between the entropy $(E)$ and the Mahalanobis' distance $(M h)$, that is $R=\frac{E}{M h}$. Mahalanobis' distance was calculated using Minitab software via PCA, which generated three principal components and stored this distance. The entropy value was calculated according to Eq. (26), where $w_{i}$ represents the weight.

$$
-\sum_{i=1}^{n} w_{i} \times \ln \left(w_{i}\right)
$$

The maximal value for $R$ was chosen, since it is expected a small value for the $M h$ and a large value for $E$. Finally, the optimal values for $w_{1}, w_{2}$, and $w_{3}$ are $0.3333,0.3333$, and 0.3333 . For these weights, the optimized values for $W f, V, C t$, and $F r$ are $0.215,0.269,0.536,-0.380$, respectively. These are coded values, indicating that the uncoded values for the same factors are $3.243 \mathrm{~m} / \mathrm{min}, 21.904 \mathrm{~V}, 14.143 \mathrm{~mm}$, and $1.924 \mathrm{~Hz}$, respectively. Therefore, the original variables $Y, D, R I$, and $P I$ are, respectively, equal to $84.14 \%, 63.28 \%, 0.5953,1.2387$ according to the model developed in this paper. It is an interesting result, since it allows satisfactory yield and values related to the geometry of the weld bead

\section{Validation experiment}

In order to validate whether the results obtained in the previous section are really practicable, a validation experiment was performed and the specimen is shown in Fig. 11. Table 11 shows the results obtained with the specifications for the parameters, and the percentage of error associated.

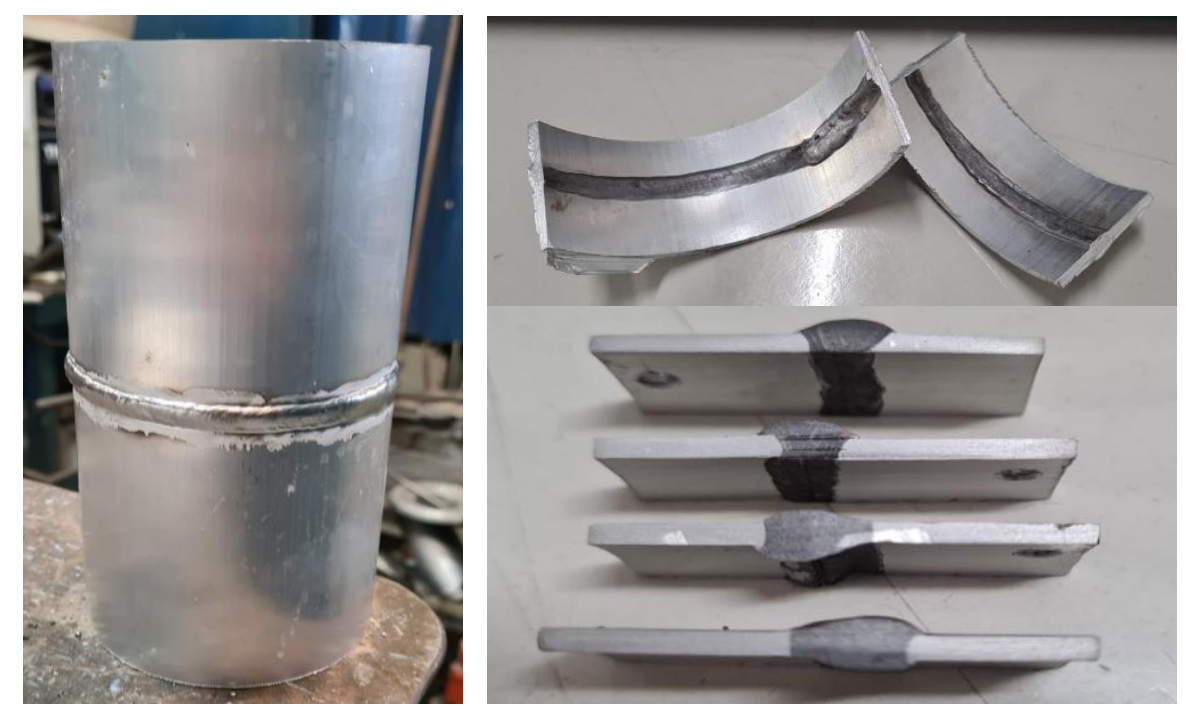

Figure 11. Validation specimen 
Table 11. Comparative table between predicted and real values for the investigated responses

\begin{tabular}{cccccc}
\hline Parameters & & \multicolumn{2}{c}{ Predicted responses } & \multicolumn{2}{c}{ Real responses values } \\
\hline$W f$ & 3.243 & $Y$ & 84.14 & $Y$ & 86.00 \\
\hline$V$ & 21.904 & $D$ & 63.28 & $D$ & 66.50 \\
\hline$C t$ & 14.143 & $R I$ & 0.5953 & $R I$ & 0.5034 \\
\hline$F r$ & 1.924 & $P I$ & 1.2387 & $P I$ & 1.3762 \\
\hline
\end{tabular}

Figure 12 shows some microscopical images of the validation specimen, each one of them represents one quadrant.

\section{Conclusion}

The present paper proposed the application of a methodology based on Poisson regression, multivariate constraints to optimize, through normal boundary intersection method, a multiobjective problem considering the welding process of aluminum alloy (AA) $6063 \mathrm{~T} 4$ tubes used in corona rings.

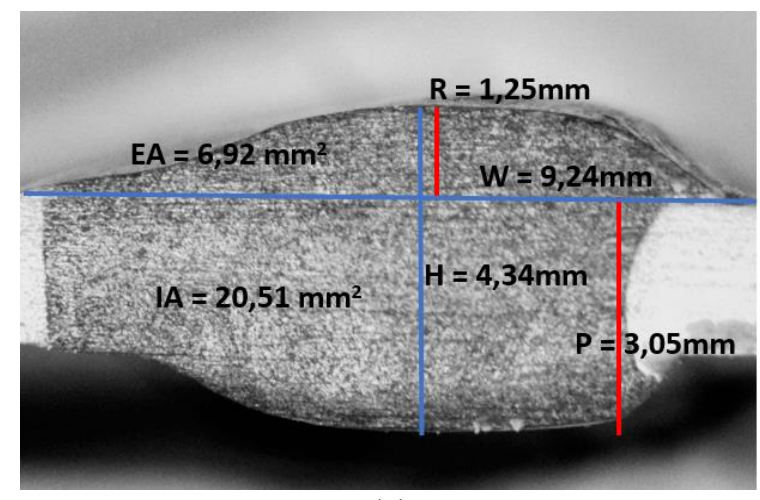

(a)

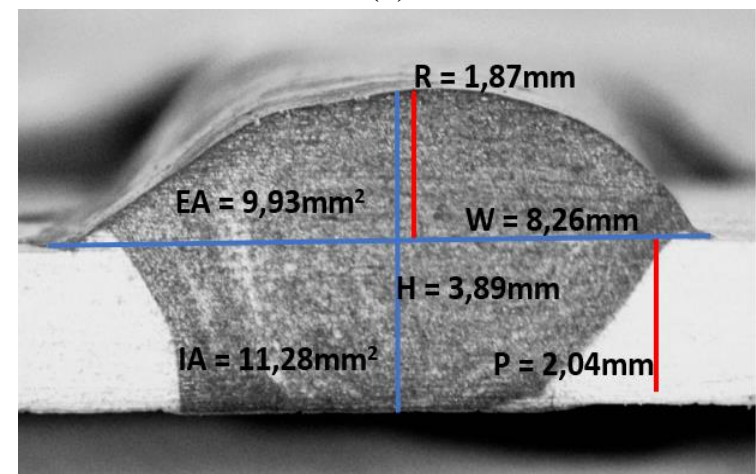

(c)

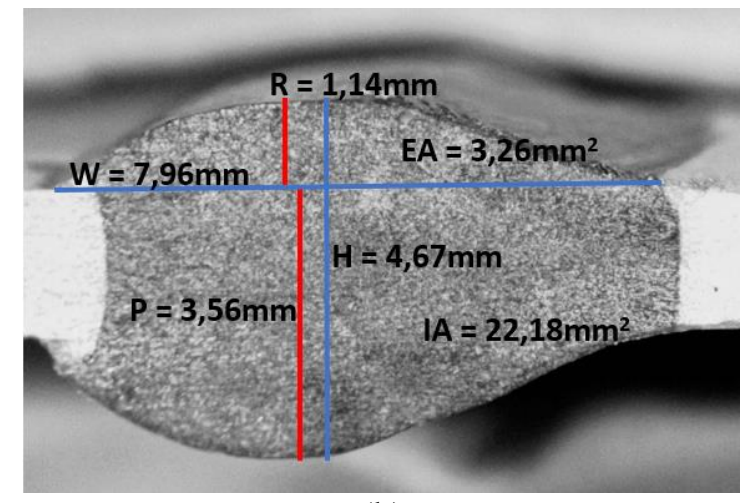

(b)

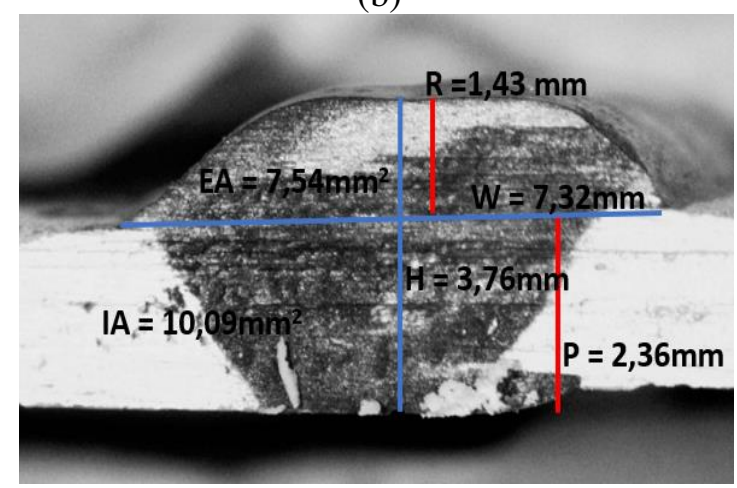

(d)

Figure 12. Validation specimen from the perspective of each quadrants

Although the difficulties of welding aluminum alloys, the paper proved that it is possible to obtain satisfactory results through an accurate adjustment of the most significant parameters (or factors) and identification of their ranges. Design of experiments, for instance, allowed the 
exploration of distinct scenarios making it easier to interpret the effects of the parameters and their interaction. Thirty-one experiments structured according to a face centered composite design with 4 factors, wire feed rate, arc voltage, contact tip to the workpiece distance and motor frequency, was carried out.

Poisson regression was an important and adequate technique to model the objective functions being considered, yield, dilution, reinforcement index, and penetration index. Furthermore, since these responses were correlated, they could not be considered separately, and the elliptical constrains, and constraints based on simultaneous confidence intervals ensured that the multivariate nature of the problem was considered.

Additionally, it was possible to observe that using factors to represent the original variables and factor mean square errors as objective functions was suitable, since the problem could be solved through normal boundary intersection, and it was also confirmed via validation experiment.

Finally, it was possible to observe that a satisfactory weld bead with large values of penetration index, dilution and yield and a small value of reinforcement index, was reached as pre specified by the manager of the process. Even though the aluminum welding process stands out due to its complexity, its optimization improved the visual quality, reduced costs, and presented a uniform and continuous weld bead as expected.

\section{Acknowledgements}

The authors would like to thank the Brazilian agencies of CAPES, CNPq, and FAPEMIG for supporting this research.

Ethical approval: Not applicable

Consent to participate: Not applicable

Consent for publication: Not applicable

Authors contribution: L.R.M., A.P.P., P.P.B., resources; A.P.P., E.R.L., S.C.S., E.L.R., P.P.B., investigation; E.R.L., E.L.R., S.C.S., data curation; S.C.S., E.L.R., E.R.L., writing-original draft preparation; E.L.R., S.C.S., E.R.L., L.R.M., writing - review and editing; A.P.P., E.R.L., S.C.S., E.L.R., P.P.B., visualization; A.P.P., P.P.B., supervision. All of the authors have read and agreed to publish this version of the manuscript.

Funding: This research received no external funding.

Conflicts of interest / Competing interests: The authors declare no conflict of interest.

Availability of data and materials: All the data are available in the paper

\section{References}


1. Ílhan S, Ozdemir A (2007) Effects of corona ring design and its location on electric field intensity and potential distribution along an insulator string. In: International Review of Electrical Engineering. pp 3408-3413

2. Murawwi E Al, Mohammed A, Alip Z, Ei-Hag A (2013) Optimization of corona ring design for a 400KV non-ceramic insulator. 2013 IEEE Electr Insul Conf EIC 2013 370373. https://doi.org/10.1109/EIC.2013.6554269

3. Abderrazzaq MH, Abu Jalgif AM (2013) Characterizing of corona rings applied to composite insulators. Electr Power Syst Res 95:121-127. https://doi.org/10.1016/j.epsr.2012.08.010

4. Rezaei A, Ehsanifar M, Wood DA (2019) Reducing welding repair requirements in refinery pressure vessel manufacturing: a case study applying six sigma principles. Int $\mathbf{J}$ Interact Des Manuf 13:1089-1102. https://doi.org/10.1007/s12008-019-00573-8

5. Meseguer-Valdenebro JL, Martinez-Conesa EJ, Serna J, Portoles A (2016) Influence of the welding parameters on the heat affected zone for aluminum welding. Therm Sci 20:643-653. https://doi.org/10.2298/TSCI140503106M

6. Braguine TB, Alcântara DS de, Castro CAC, Santos GHR dos (2018) Influência dos Parâmetros de Soldagem em Tubos de Alumínio AA6063 pelo Processo CDFW. Soldag Inspeção 23:3-16. https://doi.org/10.1590/0104-9224/si2301.02

7. Senthil SM, Parameshwaran R, Ragu Nathan S, et al (2020) A multi-objective optimization of the friction stir welding process using RSM-based-desirability function approach for joining aluminum alloy 6063-T6 pipes. Struct Multidiscip Optim 1117-1133. https://doi.org/10.1007/s00158-020-02542-2

8. Miguel V, Marín-Ortiz F, Manjabacas MC, et al (2015) Optimización multiobjetivo del proceso de soldeo GMAW de la aleación AA 6063-T5 basado en la penetración y en la zona afectada térmicamente. Rev Metal 51:1-10. https://doi.org/10.3989/revmetalm.037

9. Martinez-Conesa EJ, Egea JA, Miguel V, et al (2017) Optimization of geometric parameters in a welded joint through response surface methodology. Constr Build Mater 154:105-114. https://doi.org/10.1016/j.conbuildmat.2017.07.163

10. Meseguer-Valdenebro JL, Portoles A, Matínez-Conesa E (2018) Electrical parameters optimisation on welding geometry in the 6063-T alloy using the Taguchi methods. Int $\mathrm{J}$ Adv Manuf Technol 98:2449-2460. https://doi.org/10.1007/s00170-018-2395-x

11. Duarte Costa DM, Brito TG, de Paiva AP, et al (2016) A normal boundary intersection with multivariate mean square error approach for dry end milling process optimization of the AISI 1045 steel. J Clean Prod 135:1658-1672. https://doi.org/10.1016/j.jclepro.2016.01.062

12. Koli Y, Yuvaraj N, Aravindan S, Vipin (2020) Multi-response Mathematical Modeling for Prediction of Weld Bead Geometry of AA6061-T6 Using Response Surface 
Methodology. Trans Indian Inst Met 73:645-666. https://doi.org/10.1007/s12666-02001883-2

13. Luz ER, Romão EL, Streitenberger SC, et al (2021) A new multiobjective optimization with elliptical constraints approach for nonlinear models implemented in a stainless steel cladding process. Int J Adv Manuf Technol. https://doi.org/10.1007/s00170-020-06581-3

14. Santos MC, Machado AR, Sales WF, et al (2016) Machining of aluminum alloys: a review. Int J Adv Manuf Technol 86:3067-3080. https://doi.org/10.1007/s00170-016-8431-9

15. Jr. WDC, Rethwisch DG (2014) Materials Science and Engineering An introduction, 9th ed. John Wiley \& Sons, Inc., Honoken, New Jersey

16. Li Y, Zou W, Lee B, et al (2020) Research progress of aluminum alloy welding technology. Int J Adv Manuf Technol 109:1207-1218. https://doi.org/10.1007/s00170020-05606-1

17. Feng L, Shi Y (2017) A simulation study on the distributions of disturbances in the GARCH model. Cogent Econ Financ 5:. https://doi.org/10.1080/23322039.2017.1355503

18. Bardel D, Nelias D, Robin V, et al (2016) Residual stresses induced by electron beam welding in a 6061 aluminium alloy. J Mater Process Technol 235:1-12. https://doi.org/10.1016/j.jmatprotec.2016.04.013

19. Pakdil M, Çam G, Koçak M, Erim S (2011) Microstructural and mechanical characterization of laser beam welded AA6056 Al-alloy. Mater Sci Eng A 528:73507356. https://doi.org/10.1016/j.msea.2011.06.010

20. FADAEIFARD F, MATORI KA, GARAVI F, et al (2016) Effect of post weld heat treatment on microstructure and mechanical properties of gas tungsten arc welded AA6061-T6 alloy. Trans Nonferrous Met Soc China (English Ed 26:3102-3114. https://doi.org/10.1016/S1003-6326(16)64442-4

21. Sakthivel P, Manobbala V, Manikandan T, et al (2020) Investigation on mechanical properties of dissimilar metals using MIG welding. Mater Today Proc 37:531-536. https://doi.org/10.1016/j.matpr.2020.05.488

22. De Motta RS, Afonso SMB, Lyra PRM (2012) A modified NBI and NC method for the solution of N-multiobjective optimization problems. Struct Multidiscip Optim 46:239259. https://doi.org/10.1007/s00158-011-0729-5

23. Das I, Dennis JE (1998) Normal-Boundary Intersection: A New Method for Generating the Pareto Surface in Nonlinear Multicriteria Optimization Problems. SIAM J Optim 8:631-657. https://doi.org/10.1137/S1052623496307510

24. Mattiussi A, Rosano M, Simeoni P (2014) A decision support system for sustainable energy supply combining multi-objective and multi-attribute analysis: An Australian case study. Decis Support Syst 57:150-159. https://doi.org/10.1016/j.dss.2013.08.013

25. Costa DMD, Paula TI, Silva PAP, Paiva AP (2016) Normal boundary intersection method 
based on principal components and Taguchi's signal-to-noise ratio applied to the multiobjective optimization of 12L14 free machining steel turning process. Int J Adv Manuf Technol 87:825-834. https://doi.org/10.1007/s00170-016-8478-7

26. De Freitas Gomes JH, Júnior ARS, De Paiva AP, et al (2012) Global Criterion Method based on principal components to the optimization of manufacturing processes with multiple responses. Stroj Vestnik/Journal Mech Eng 58:345-353. https://doi.org/10.5545/sv-jme.2011.136

27. Oujebbour F, Habbal A, Ellaia R (2013) Optimization of concurrent criteria in the stamping process. In: Proceedings of 2013 International Conference on Industrial Engineering and Systems Management (IESM). pp 1-10

28. de Almeida FA, Santos ACO, de Paiva AP, et al (2020) Multivariate Taguchi loss function optimization based on principal components analysis and normal boundary intersection. Eng Comput. https://doi.org/10.1007/s00366-020-01122-8

29. Moura D, Barcelos V, Samanamud GRL, et al (2018) Normal boundary intersection applied as multivariate and multiobjective optimization in the treatment of amoxicillin synthetic solution. Environ Monit Assess 190:. https://doi.org/10.1007/s10661-018-65238

30. Naves FL, de Paula TI, Balestrassi PP, et al (2017) Multivariate Normal Boundary Intersection based on rotated factor scores: A multiobjective optimization method for methyl orange treatment. J Clean Prod 143:413-439. https://doi.org/10.1016/j.jclepro.2016.12.092

31. Montgomery DC (2017) Design and Analysis of Experiments, 9th ed. John Wiley \& Sons, New York

32. Singh D, Rao PV (2007) A surface roughness prediction model for hard turning process. Int J Adv Manuf Technol 32:1115-1124. https://doi.org/10.1007/s00170-006-0429-2

33. Moghaddas MA (2021) Modeling and optimization of thrust force, torque, and surface roughness in ultrasonic-assisted drilling using surface response methodology. Int J Adv Manuf Technol 112:2909-2923. https://doi.org/10.1007/s00170-020-06380-w

34. Ali MA, Ishfaq K, Jawad M (2019) Evaluation of surface quality and mechanical properties of squeeze casted AA2026 aluminum alloy using response surface methodology. Int J Adv Manuf Technol 103:4041-4054. https://doi.org/10.1007/s00170019-03836-6

35. Natarajan U, Periyanan PR, Yang SH (2011) Multiple-response optimization for microendmilling process using response surface methodology. Int J Adv Manuf Technol 56:177-185. https://doi.org/10.1007/s00170-011-3156-2

36. Ribeiro R, Romão EL, Costa S, et al (2020) Optimization of the resistance spot welding process of 22MnB5-galvannealed steel using response surface methodology and global 
criterion method based on principal components analysis. Metals (Basel) 10:. https://doi.org/10.3390/met10101338

37. Saad MS, Nor AM, Baharudin ME, et al (2019) Optimization of surface roughness in FDM 3D printer using response surface methodology, particle swarm optimization, and symbiotic organism search algorithms. Int J Adv Manuf Technol 105:5121-5137. https://doi.org/10.1007/s00170-019-04568-3

38. Meyers RH, Montgomery DC, Anderson-Cook CM (2009) Response Surface Methodology Process and product optimization using designed experimetns, Fourth. John Wiley \& Sons, Inc., Honoken, New Jersey

39. Agresti A (2015) Foundations Linear Generalized Linear Models

40. Meyers RH, Montgomery DC, Vining GG, Robinson TJ (2005) Generalized Linear Models with Applications ins Engineering and the Sciences, Second. John Wiley \& Sons, Inc., Hoboken, New Jersey

41. De Paiva AP, Gomes JHF, Peruchi RS, et al (2014) A multivariate robust parameter optimization approach based on Principal Component Analysis with combined arrays. Comput Ind Eng 74:186-198. https://doi.org/10.1016/j.cie.2014.05.018

42. Johnson RA, Wichern DW (2007) Applied multivariate statistical analysis, Sixth. Pearson Education, Inc., Upper Saddle River, New Jersey

43. de Almeida FA, Santos ACO, de Paiva AP, et al (2020) Multivariate Taguchi loss function optimization based on principal components analysis and normal boundary intersection. Eng Comput. https://doi.org/10.1007/s00366-020-01122-8

44. Leite RR (2019) Método de interseção normal à fronteira para modelos quadráticos de escores fatoriais rotacionais. Federal University of Itajubá

45. Paiva AP, Paiva EJ, Ferreira JR, et al (2009) A multivariate mean square error optimization of AISI 52100 hardened steel turning. Int J Adv Manuf Technol 43:631-643. https://doi.org/10.1007/s00170-008-1745-5

46. Meseguer-Valdenebro JL, Portoles A, Oñoro J (2016) Numerical study of TTP curves upon welding of 6063-T5 aluminium alloy and optimization of welding process parameters by Taguchi's method. Indian J Eng Mater Sci 23:341-348

47. Paiva AP, Costa SC, Paiva EJ, et al (2010) Multi-objective optimization of pulsed gas metal arc welding process based on weighted principal component scores. Int J Adv Manuf Technol 50:113-125. https://doi.org/10.1007/s00170-009-2504-y

48. de Almeida FA, Streitenberger SC, Torres AF, et al (2020) A gage study through the weighting of latent variables under orthogonal rotation. IEEE Access 8:183557-183570. https://doi.org/10.1109/ACCESS.2020.3019031 
Figures

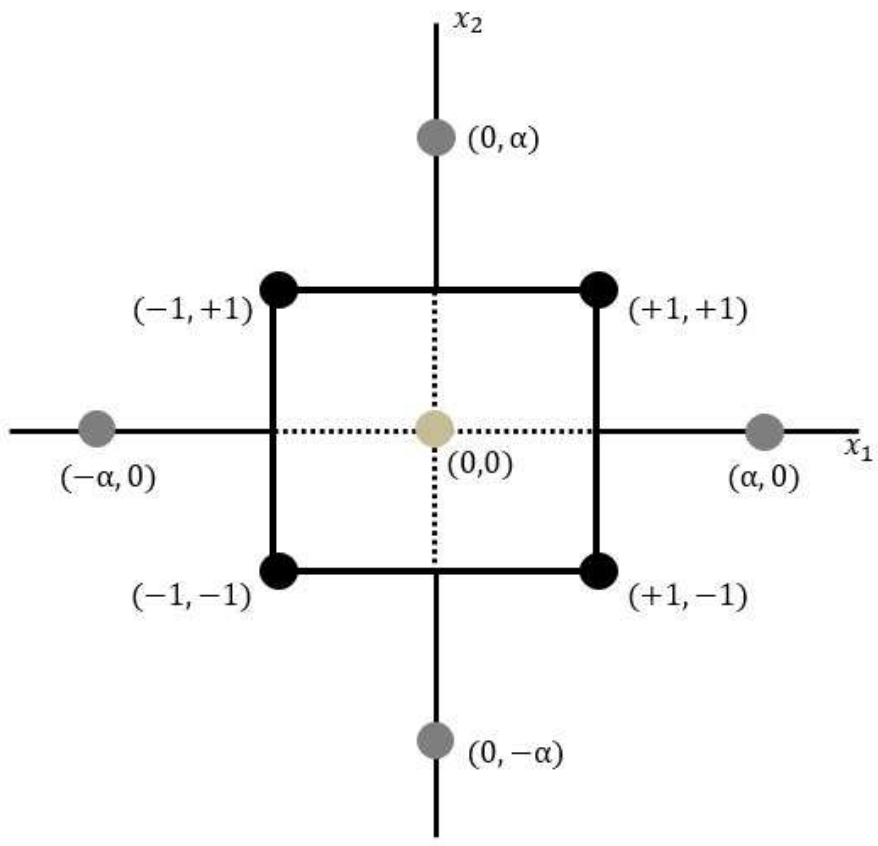

(a) $k=2$

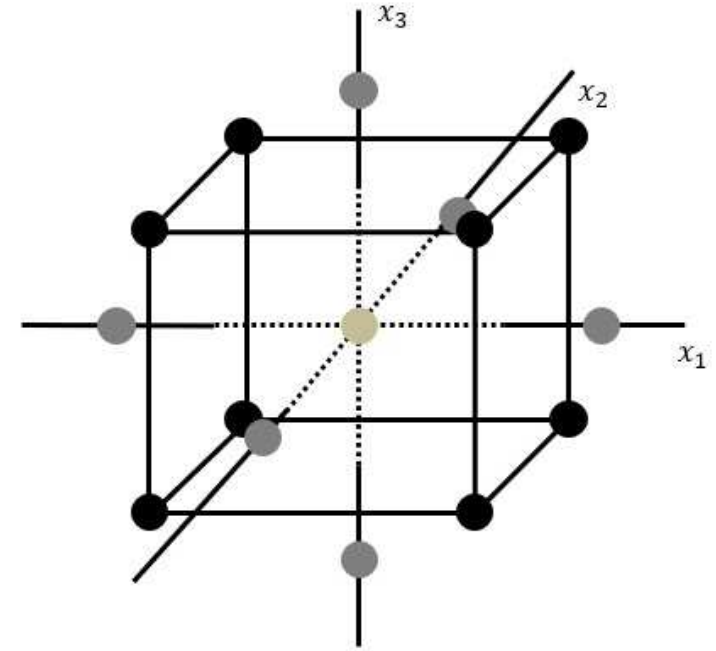

(b) $k=3$
Factorial points Axial points

Center points

\section{Figure 1}

CCD for (a) 2 and (b) 3 factors [31]
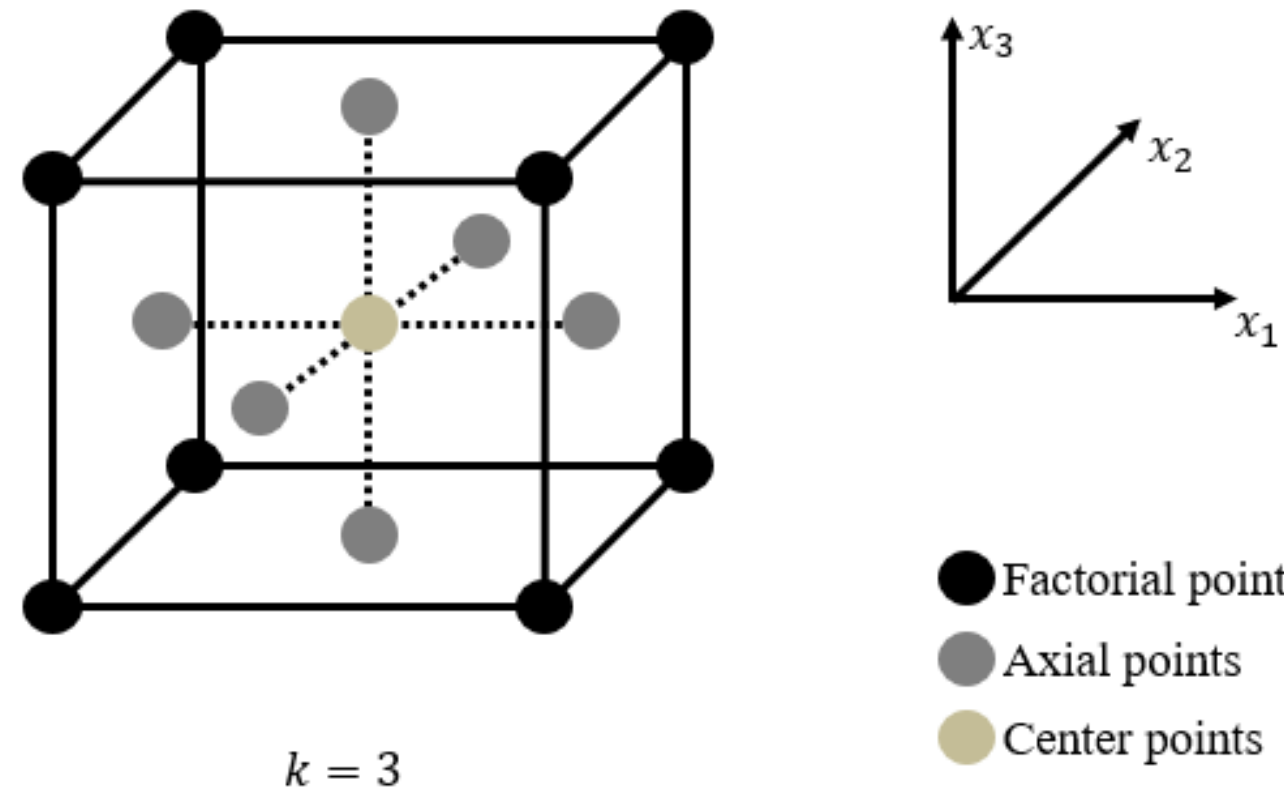

Factorial points

Axial points

Center points

Figure 2 


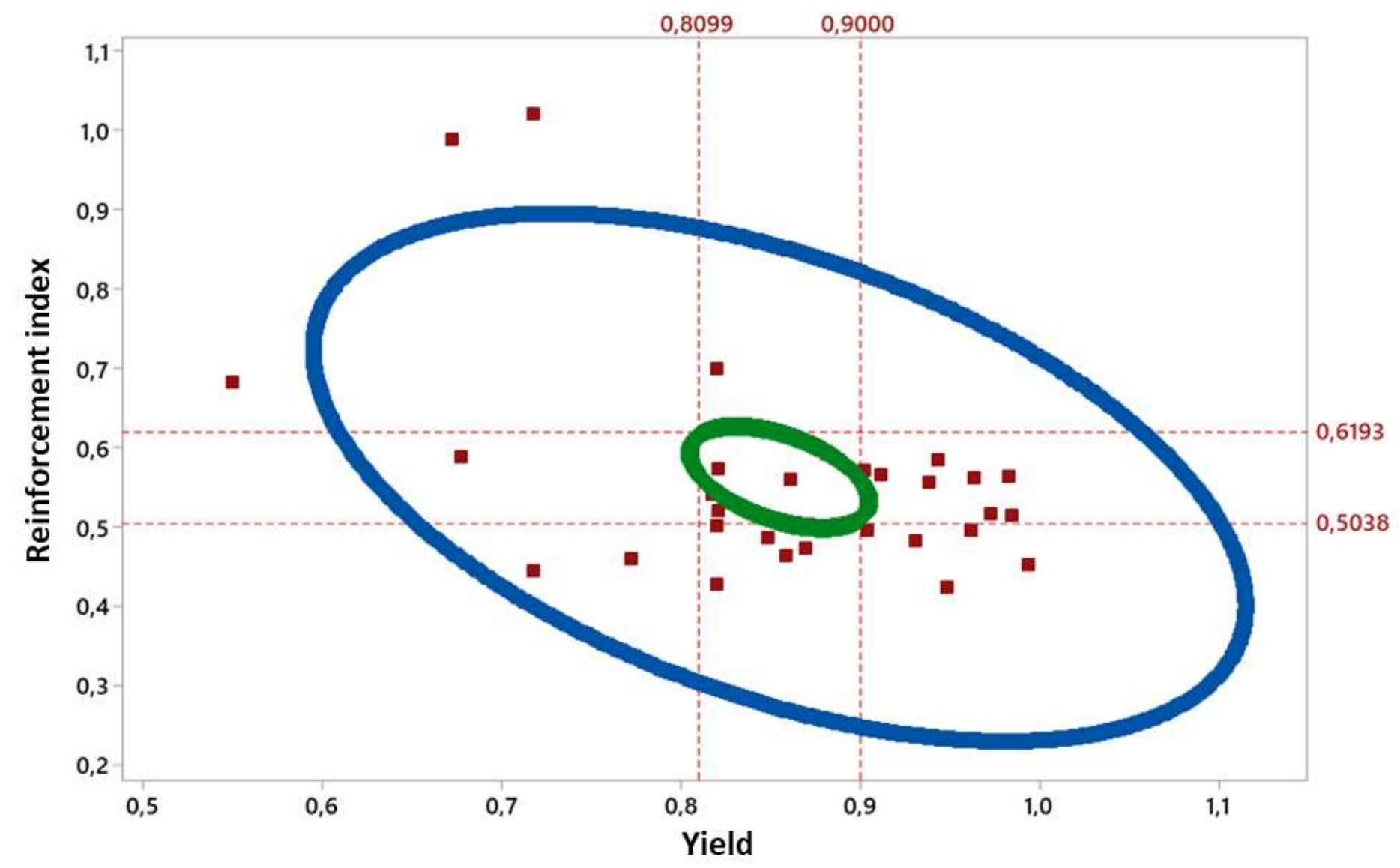

Figure 3

Ellipsoid for the mean, showing the Bonferroni intervals, and for the original data

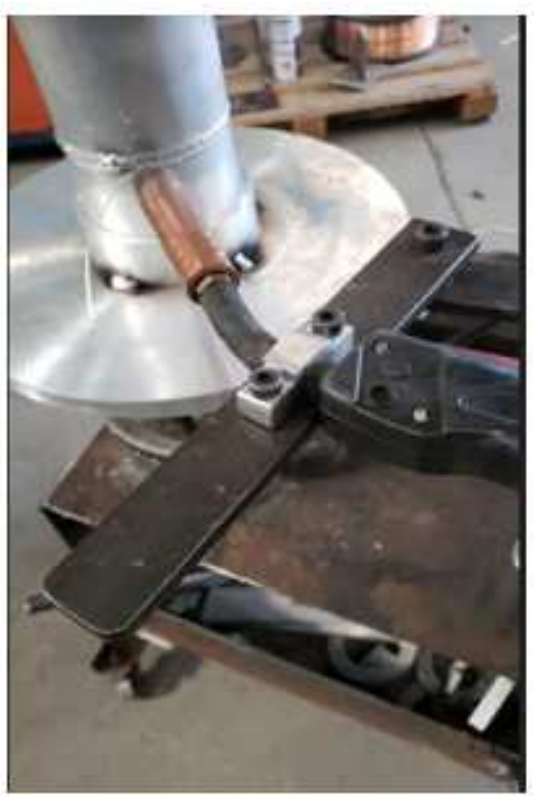

Figure 4

Semi-automatic welding process structure 


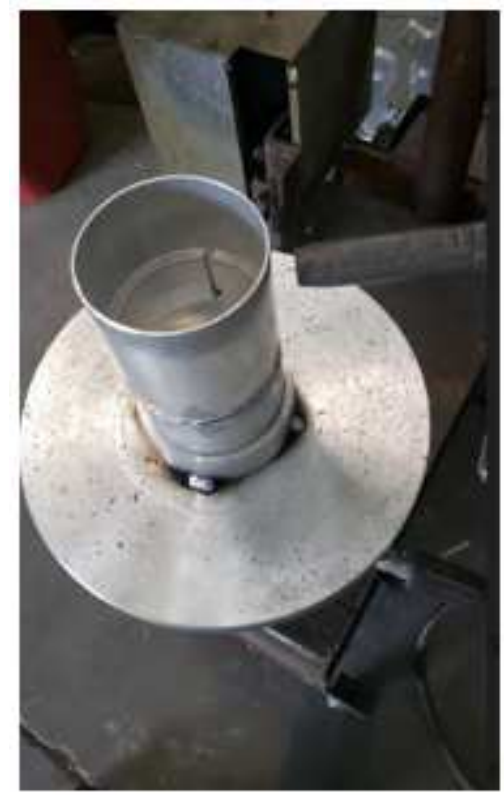

Figure 5

Inside view of the specimen and the cylindric piece

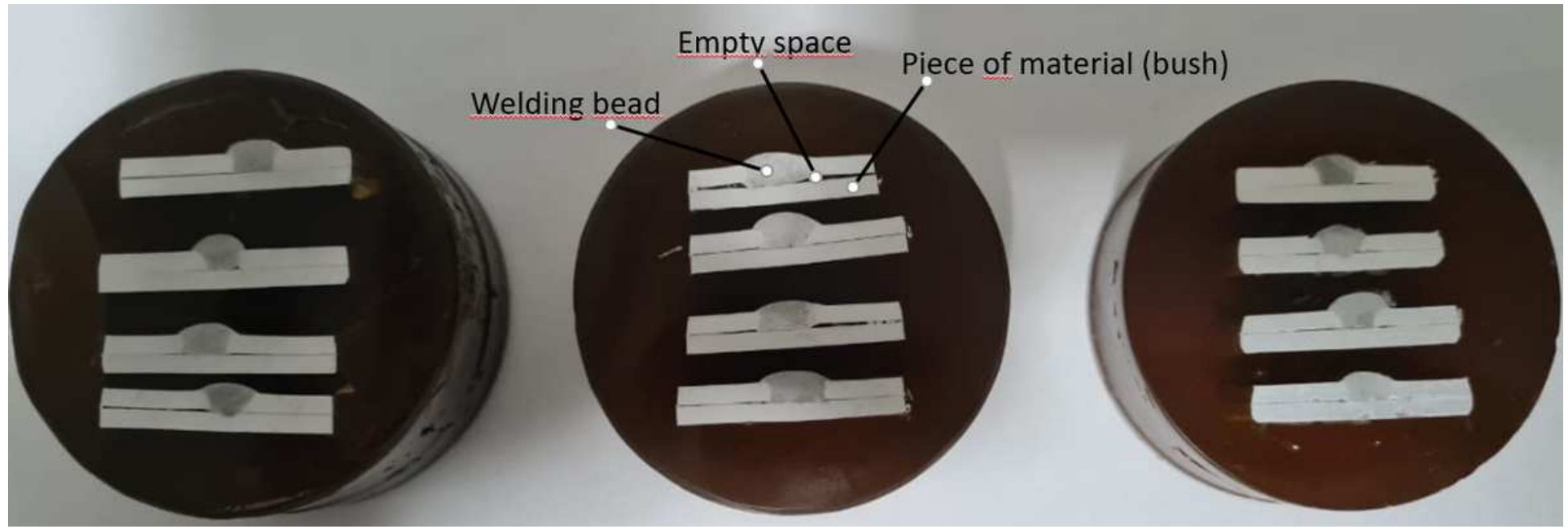

Figure 6

Specimen obtained in the runs 01,07 and 20 of the CCF
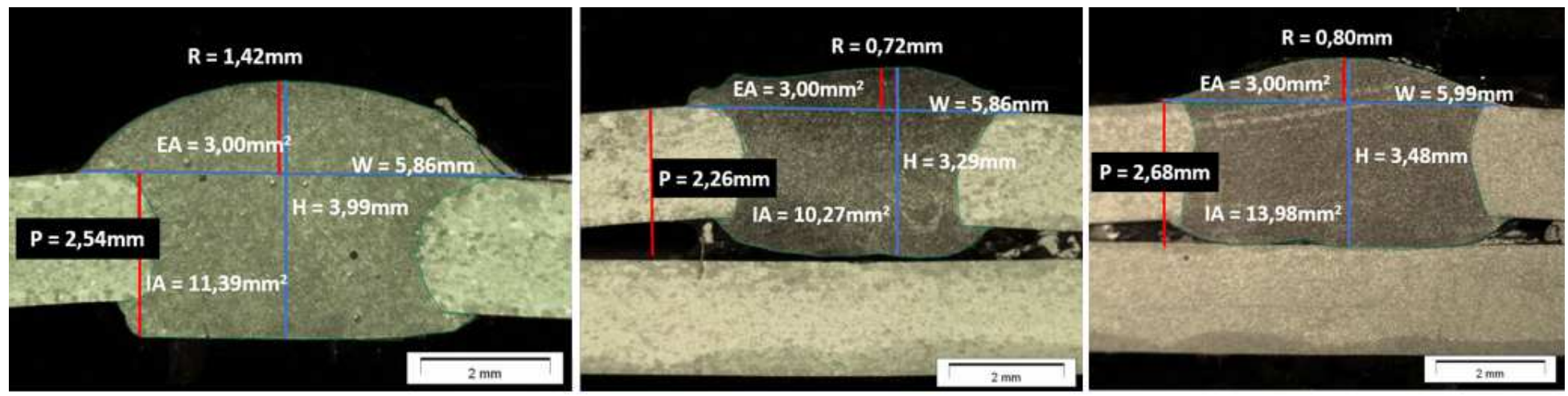
Figure 7

Images obtained from run 3,9, and 15 of the CCF and their geometry measurements

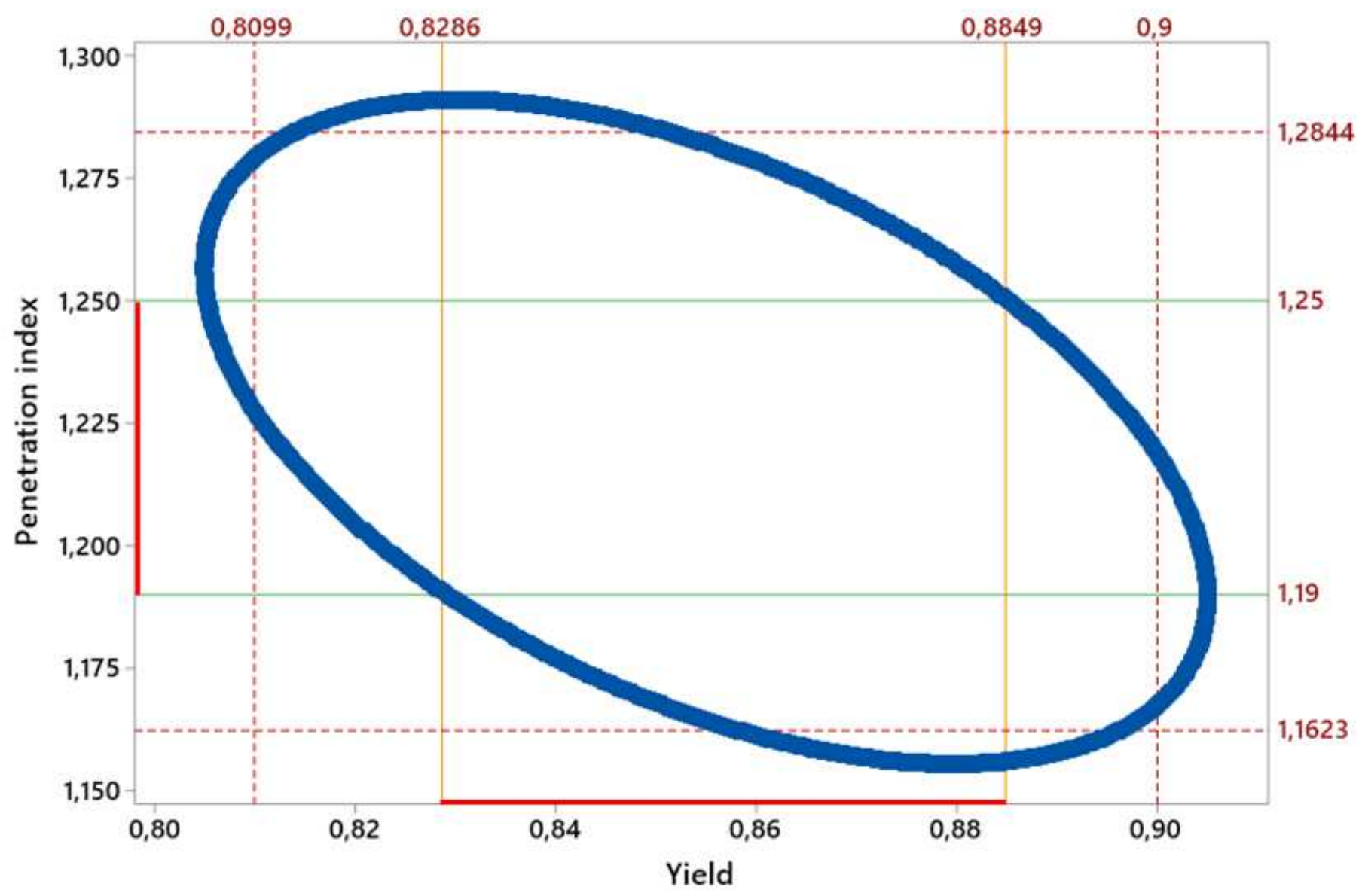

Figure 8

Elliptical region for penetration index and yield means with constraints 


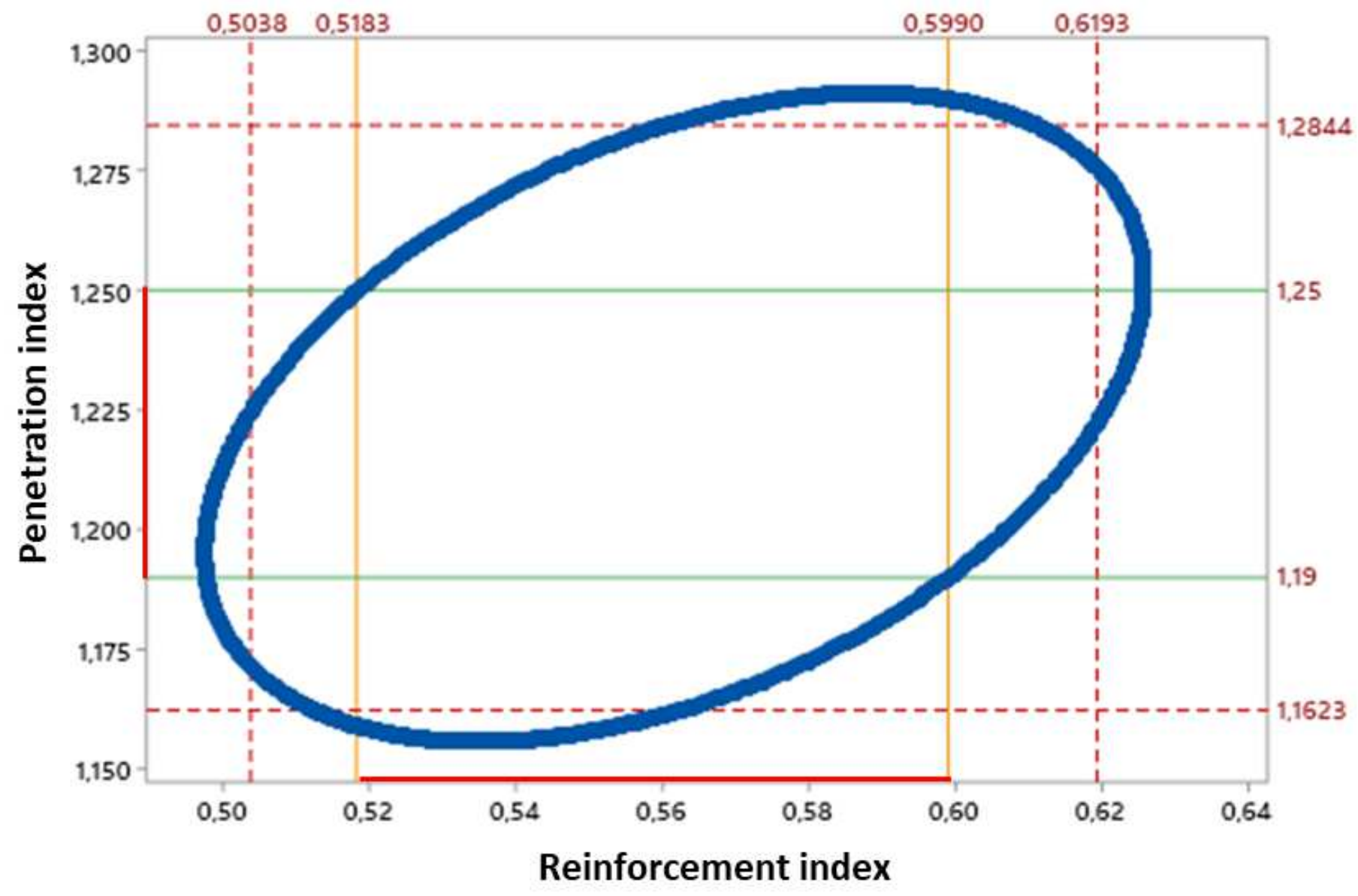

Figure 9

Elliptical region for penetration index and reinforcement index means with constraints 


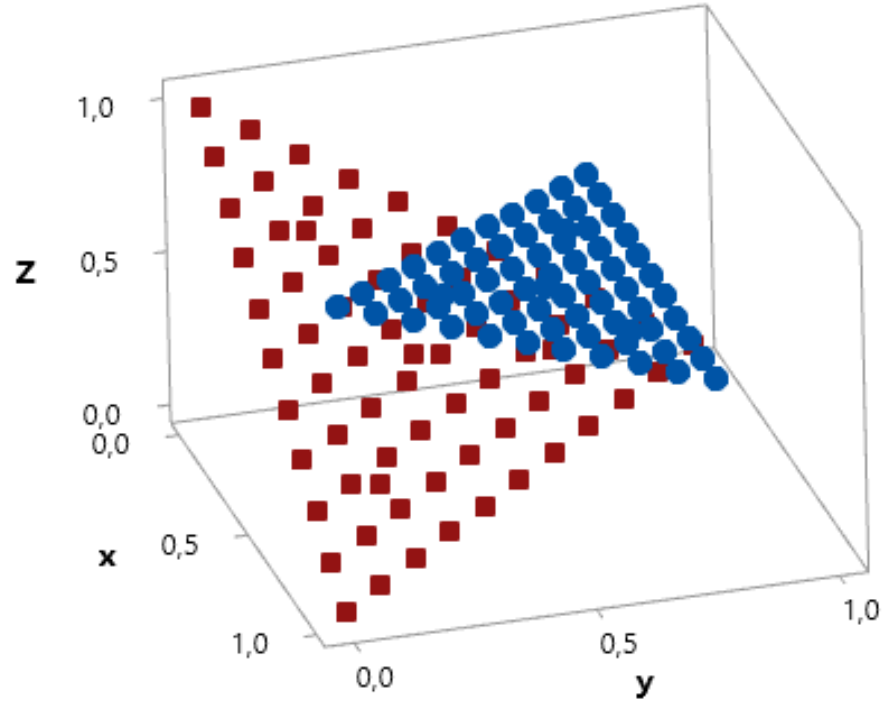

- Normalized factors

- Weights

Figure 10

3D scatterplot of the normalized factors and weights 

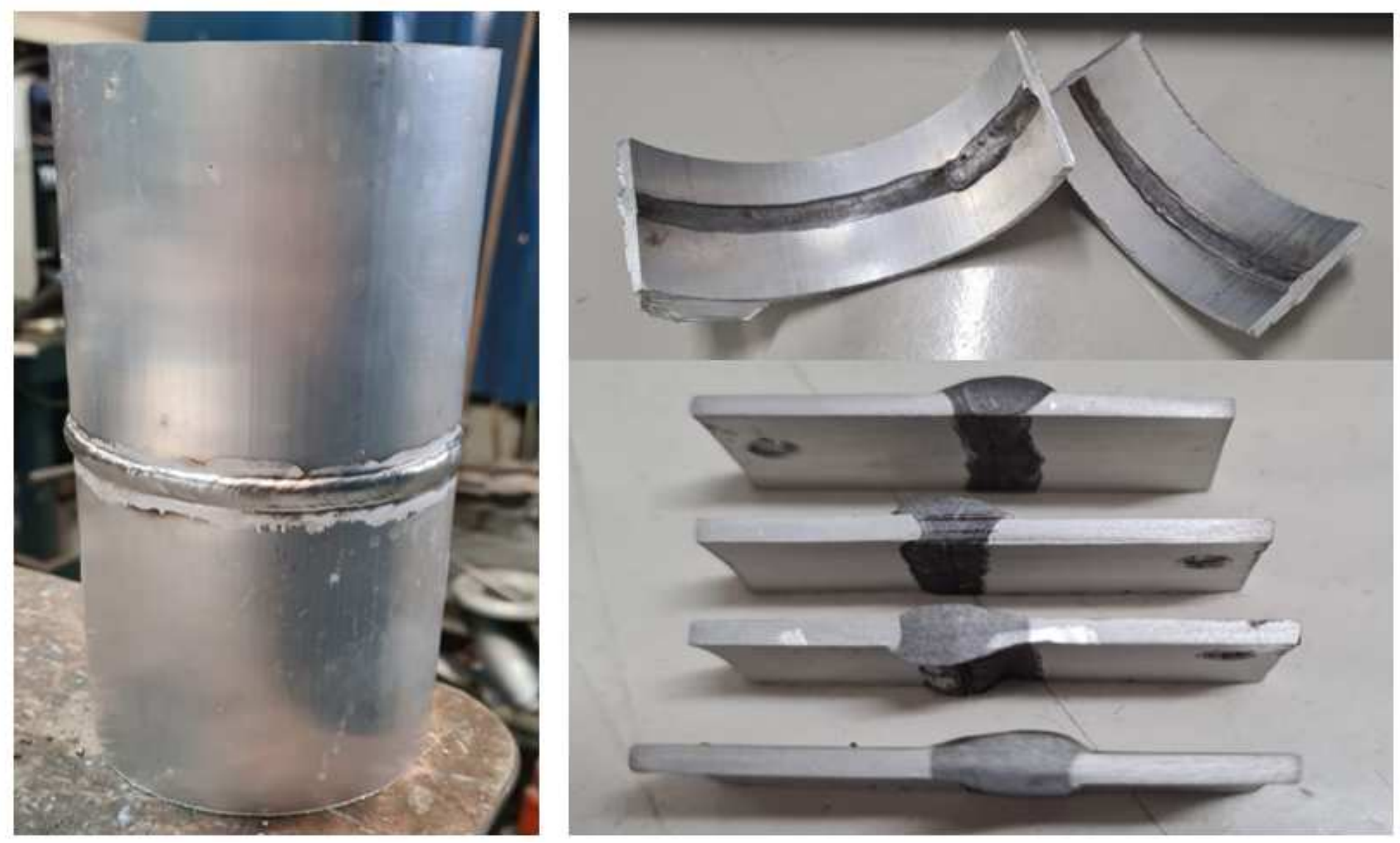

Figure 11

Validation specimen 


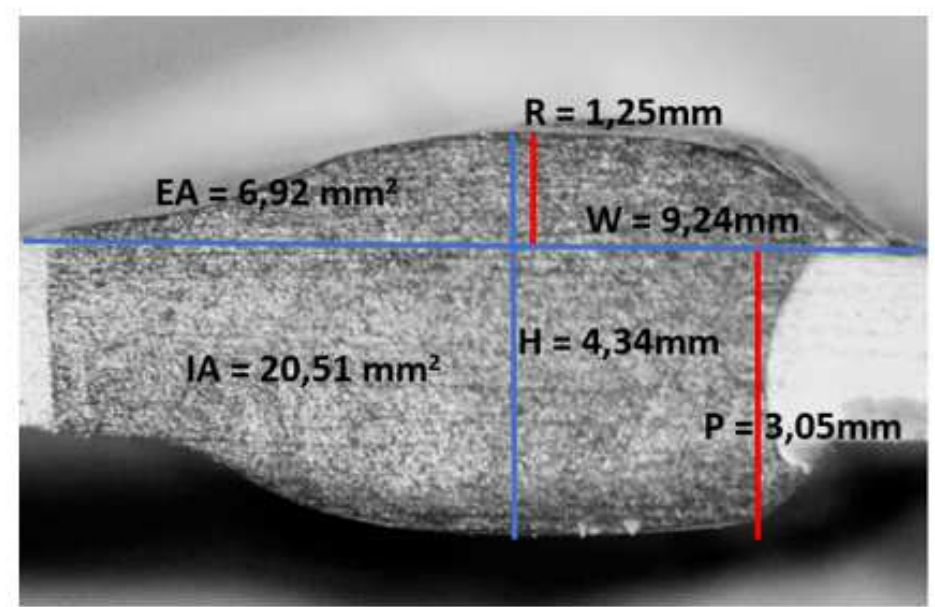

(a)

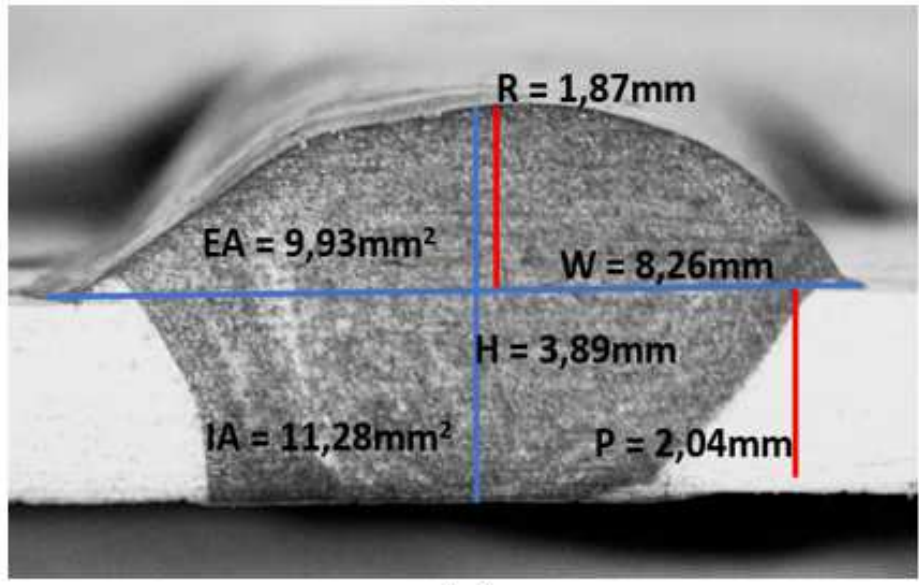

(c)

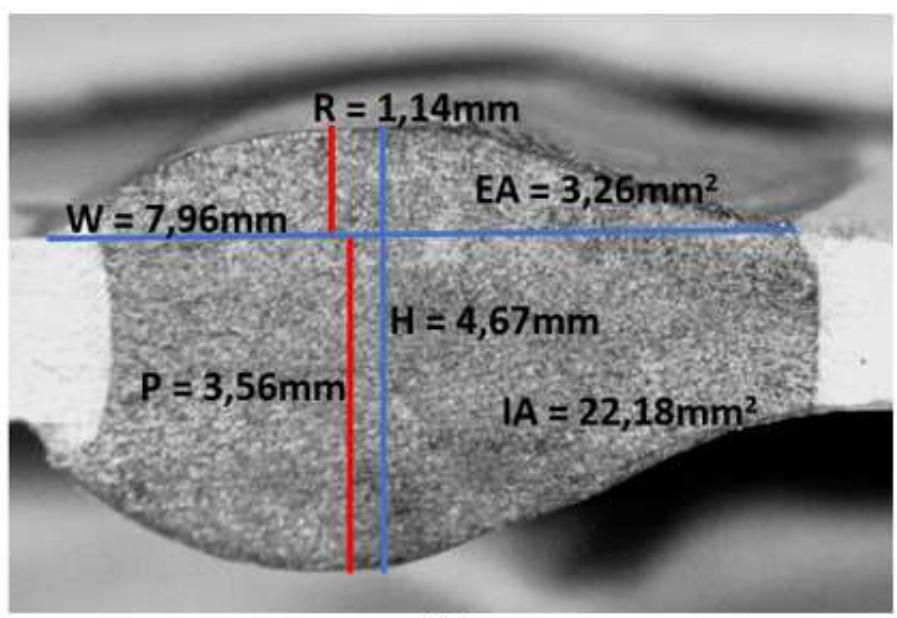

(b)

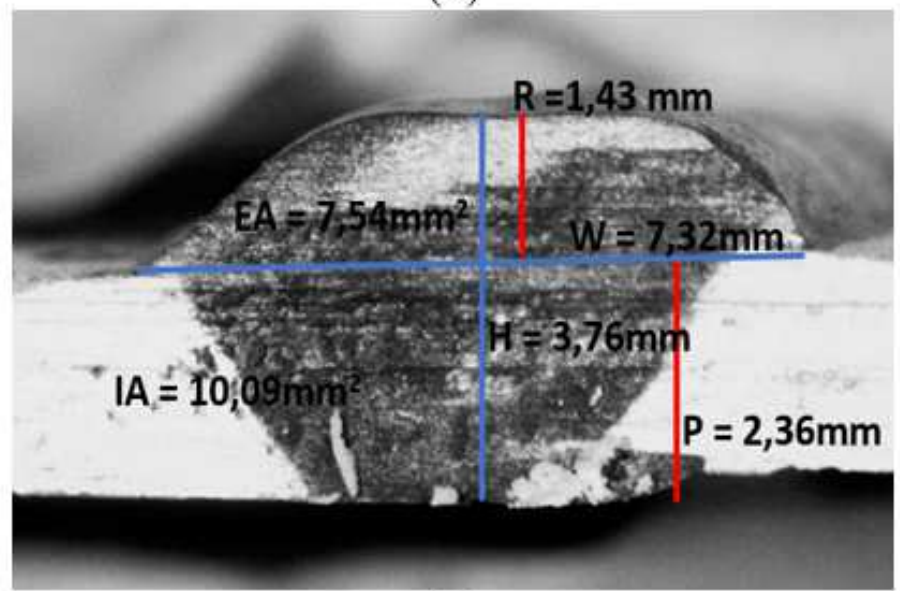

(d)

Figure 12

Validation specimen from the perspective of each quadrants 